\title{
A multi-attribute supply chain network resilience assessment framework based on SNA-inspired indicators
}

\author{
Iman Kazemian $^{\mathrm{a}}$, S. Ali Torabi ${ }^{\mathrm{a}}$ \\ ${ }^{a}$ School of Industrial Engineering, College of Engineering, University of Tehran, \\ Tehran, Iran
}

Christopher W. Zobel ${ }^{\text {b, } 1}$

${ }^{b}$ Department of Business Information Technology, Virginia Tech, Blacksburg, VA $U S A$

Yuhong $\mathrm{Li}^{\mathrm{c}}$

${ }^{c}$ Department of Information Technology \& Decision Sciences, Old Dominion University, Norfolk, VA USA

\footnotetext{
Milad Baghersad ${ }^{\mathrm{d}}$

${ }^{d}$ Information Technology \& Operations Management, Florida Atlantic University, Boca Raton, FL USA
}

\footnotetext{
${ }^{1}$ Corresponding author. Tel.: +5402311856 ; fax: +5402316596 .

E-mail addresses: i.kazemian@ut.ac.ir (Iman Kazemian); satorabi@ut.ac.ir (S. Ali Torabi); czobel@vt.edu (Christopher Zobel); y9li@odu.edu (Yuhong Li); mbaghersad@fau.edu (Milad Baghersad);
} 


\title{
A multi-attribute supply chain network resilience assessment framework based on SNA-inspired indicators
}

\begin{abstract}
This study proposes a supply chain resilience assessment framework at the network (i.e. structural) level based on quantifying supply chain networks' structural factors and their relationships to different resilience strategies, by using a hybrid DEMATEL-ANP approach. DEMATEL is used to quantify interdependencies between the structural resilience factors, and between the resilience strategies. ANP is then used to quantify the outer-dependencies among these elements and to construct the limit supermatrix from which the global weights of all the decision network's elements are estimated. To create the structural resilience factors, different network factors are selected and adopted from the social network analysis and supply chain resilience literatures. A case study is then performed to assess the performance of the proposed approach and to derive important observations to support future decision making. According to the results, the proposed approach can suitably measure the resilience performance of a supply chain network and help decision makers plan for more effective resilience improvement actions.
\end{abstract}

Keywords: Supply Chain Resilience, Social Network Analysis, Structural Analysis, DEMATELANP.

\section{Introduction}

Supply chains are composed of different facilities and other entities that are connected by the physical flow of materials or products (Gong et al., 2014). As such, we may represent them as complex interconnected networks consisting of, for example, suppliers, manufacturers, warehouses, retailers, and customers. The complexity of such networks is growing, and therefore global supply chains are becoming ever more exposed to disruptions with unanticipated consequences (Craighead et al., 2007). The United States' Hurricane Katrina in 2005, Japan's tsunami in 2011, the Thai flood in 2011, and the great earthquakes occurring in Nepal in April and May of 2015, are all examples of some of the recent disruptions worldwide.

To illustrate the importance of such disasters' impacts on supply chains, one may investigate Toyota's supply chain disruption during 2011 and 2012. After the Japanese tsunami, Toyota was faced with a serious supply disruption for six months due to a supply shortage from some of their Japanese suppliers. This led to the need for Toyota to idle some 
of their North American plants (Kim et al., 2011). In addition, as reported by The Economic Times, “Japan's Toyota Motor [Company]...cut production at its Indian subsidiary by up to 70\% between April 25 and June 4 due to disruption of supplies” (Bureau, 2011).

Research on supply chain resilience has largely focused on assessing vulnerabilities that facilities may face and/or capabilities that they need to have to manage these vulnerabilities (Ellis et al., 2010). However, in many instances, like with Toyota's supply chain disruption during 2011 and 2012, supply disruptions (i.e. shortages of incoming material flow) are not initiated from a facility, but rather from its supply chain network (SCN) structure. Also, disruptions at the local level do not necessarily lead to network level disruptions (Kim et al., 2011, 2015). In order to prevent or lessen the impacts of potential disruptions, managers therefore also have begun to study the interrelationships between facilities and the underlying infrastructure of the supply chain networks. By developing a better understanding of the relationships between these different components, they can subsequently plan to take more effective actions to improve the resilience of the whole SCN. Parkhe, Wasserman, and Ralston (2006) showed that "networks are reshaping the global business architecture"; reflecting on the growing nature of the network perspective on individuals, groups, organizations and industry interactions. This is particularly evident within management research and practice where networks and relational capabilities provide a fundamental tool for organizations to leverage global SCNs (Gulati, Lavie, and Madhavan 2011). For instance, theoretical growth of business networks has meaningfully enlightened the network dimensions of market-based transactions (Monaghan, Gunnigle, and Lavelle 2014). In this light, social network analysis (SNA) is increasingly being applied as an emerging methodological tool and convenient heuristic to map and quantify relationships between interdependent actors. As such it has resulted in an array of research endorsing the theoretical and mathematical components within the management specific literature (Borgatti and Cross 2003).

Social network analysis (SNA) is the process of investigating social structures through the use of networks and graph theory. The SNA approach includes several factors to assess the behavioral aspects of complex networks. As opposed to other approaches, SNA is based on relational aspects of the different components of a network; therefore, the basic structural factors (that are key to a comprehensive analysis of complex networks), can be analyzed (Edwards, 2010). SNA characterizes networked structures in terms of nodes (individual 
actors, people, or resources within the network) and the ties, edges, or links (relationships or interactions) that connect them. From a network perspective, a supply chain can be viewed as a set of actors, represented by facilities, which are linked together by different types of relationships, such as the physical flow of material, the virtual flow of information, friendships, competitions, etc. The assessed impacts of a supply disruption are then determined both by the effects on the individual actors and by the network structure. Understanding the overall network structure, and being able to differentiate between the impacts associated with different types of structures, can therefore lead to better management of disruptions, both strategically and operationally.

Given this context, the main motivation behind this current research effort is to address one of the key challenges raised by contemporary supply chain researchers who argue that a resilient supply chain network's structure should take heed of quantitative factors (Cardoso et al., 2015). The present study thus aims to contribute to the literature by identifying the major aspects of a resilient SCN's structure and proposing a resilience assessment model at the network level that uses social network analysis (SNA)-inspired indicators in a multi-attribute decision making (MADM) context, to help decision makers quantify the resilience of their SCNs. In other words, the focus of this work is on examining the structural complexity of SCNs from the resilience viewpoint. With this in mind, the main findings (i.e. contributions) of this paper are as follows:

- First of all, the paper presents a systematic resilience assessment framework that uses a hybrid MADM methodology to investigate the interrelationships between the components of a SCN. When decision makers evaluate the effectiveness of different alternatives for improving supply chain resilience on the basis of multiple criteria, the tradeoffs between these criteria can complicate the problem, and thus more sophisticated methods are needed (Tzeng and Huang, 2011). Adopting a structured resilience assessment framework allows them to deal more effectively with such multi-attribute decision making (MADM) problems.

One of the hybrid MADM approaches that has been shown to efficiently manage the difficulty of considering interdependencies / interrelationships among different criteria is DEMATEL-ANP (Yang and Tzeng, 2011; Fazli et al., 2015). This approach can help 
decision makers calculate the total resilience level of a SCN and allow them to make more informed decisions regarding different design aspects of their SCNs, such as the average path length in the network, the network diameter, the overall closeness centrality of source nodes, the proportion of suppliers, the network density, etc. Decision makers can then calculate the resilience level of the overall supply chain by incorporating both available subjective and objective data. This study shows that increasing redundancy by adding extra nodes or arcs to increase the network's density might not improve the resilience of a SCN. In particular, suppliers' locations and how they are connected in the network; should be given careful attention. For example, in the case of adding extra suppliers to the network, the DMs should take into account the average path length from the candidate suppliers to the other nodes, in order to have a more resilient supply chain structure than before. The results of applying this method, as discussed below, indicate that suppliers become more important according to their locations and how they are connected together in the supply chain.

- Secondly, in addition to validating the use of existing SNA-inspired network factors at the SNA literature as the SCN's resilience indicators, the paper defines several new supply chain design factors, namely "overall clustering", "overall closeness centrality", "overall degree centrality", "overall betweenness centrality", "overall flow complexity", and “overall degree centrality for source nodes," in order to help capture additional resilience behaviors and make the resilience analysis more comprehensive.

- Third, this research contributes to the supplier selection and management practices. Often, decision makers place emphasis on the qualities and abilities of suppliers when assessing supply chains. However, our study suggests taking a broader view and considering that a given supplier's role in the resilience of the whole supply chain depends, to some extent, on its location in the network (see Observation 3). We thus show that it is important for decision makers to map the ties among individual suppliers in the supply chain, in order to accurately evaluate their effects on the network's resilience.

The rest of the paper is organized as follows. Section 2 reviews the related literature. Section 3 elaborates on the proposed supply chain resilience assessment framework, which accounts for supply chain resilience factors, strategies, and capacity making categories, and their 
interrelationships, using a hybrid MADM approach. Section 4 provides an application of the proposed approach to three sample supply chains whose factors have been borrowed from the literature. Finally, Sections 5 and 6 provide discussion, conclusions, and future research avenues.

\section{Literature review}

Our literature review focuses on two main research streams: supply chain resilience and social network analysis, including SNA for investigating supply chain structural behavior.

\subsection{Supply chain resilience}

The concept of supply chain resilience can be defined to be the capability of the supply chain to prepare for unexpected events, respond to any associated disruptions, and then recover from those disruptions by maintaining continuity of operations at the desired level of connectedness and control over structure and function (Ponomarov and Holcomb, 2009, Sabahi and Parast, 2019). Nowadays an increasing number of papers are being published in the domain of resilient SCN design, and this topic has been recognized as a hot and emerging research area by academics (Fahimnia et al., 2015). According to Vugrin et al. (2011), the resilience capacity of a system is normally measured through three dimensions: absorptive, adaptive and restorative. An example of applying this perspective is provided in Hosseini and Barker (2016), in which they propose a Bayesian network model for supplier evaluation and selection that considers several criteria falling into the primary (or traditional), green, and resilience categories. Their model quantifies resilience in terms of absorptive, adaptive, and restorative capacities. The details of these three types of capacities are provided below.

Absorptive resilience capacity: Geographical segregation of suppliers, prepositioning surplus inventory, and contracting with backup suppliers are some examples of absorptive strategies (Hosseini and Barker, 2016). According to Vugrin et al. (2011), the absorptive capacity is an endogenous feature of the system. For example, holding extra inventories in distribution centers can enhance the absorptive capacity as supplying the customers can be continued from the prepositioned inventory while the disrupted supplier recovers. Based on the quantitative analysis of supply chain resilience provided by Hosseini et al. (2019a), the absorptive capacity of a supply chain can be divided into four categories, namely: supplier 
segregation (Hosseini and Barker 2016, Hosseini et al. 2019b), multiple sourcing strategies (Yoon et al. 2018; Ivanov et al., 2017a; Ivanov et al., 2017b), inventory prepositioning (Khalili et al., 2017; Elluru et al., 2019; Turnquist and Vugrin, 2013), and multiple transportation channels (Kamalahmadi and Parast, 2016).

Adaptive resilience capacity: Rerouting through a different transportation/delivery method during a disruption is an example of adaptive capacity. Adaptive capacity could be considered as the second line of defense against disruption and as a part of a temporary postdisaster strategy. It is a set of properties that reflects activities that result from extra effort over time, often in response to a catastrophic situation. It reflects the ability of the system to change endogenously during the recovery period. Suppose that a portable manufacturing system can be reconfigured to produce a variety of products on demand. This system could be rapidly deployed to generate the products needed to handle an unexpected situation, or to prevent shortages caused by the supplier's plant shutdown. Hosseini et al. (2019a) divided adaptive resilience capacity into backup suppliers (Torabi et al., 2015; Chakraborty et al., 2019), rerouting (Hosseini and Al Khaled, 2019; Wang et al., 2016), communication (Scholten and Schilder, 2015; Mandal et al., 2016; Levalle and Nof, 2015), and substitution (Mancheri et al. 2018).

Restorative resilience capacity: In the case of massive catastrophic events, a supply network may not be able to repair itself quickly enough to avoid unacceptably large consequences. Hosseini and Barker (2016) discussed suppliers' restoration budgets and technical resource restorations as two arms of restorative resilience capacity, which significantly helps suppliers to recover quickly. Restorative strategies usually restore the system to near its original pre-event state, but can also restore the system to a completely new state or regime that anticipates future system requirements.

Recent research efforts have begun to focus on issues related to the interconnectedness of supply chain networks, such as the "ripple effect" that occurs when a localized disruption propagates across a SCN (Hosseini and Ivanov, 2019, 2020; Hosseini et al., 2020b). The network dependencies that bind the failure of some network components to the failure of other network components can reduce network robustness, the absorptive capacity of the network, while recovery schemes can improve the restorative capacity. The effect of both dependencies 
and recovery schemes on network resilience has only recently begun to be addressed (Bai et al., 2017; Hosseini et al., 2020a).

To enhance resilience capacities, a number of different supply chain resilience strategies have been introduced, such as collaborative relationships among supply chain partners (CRSCP) (Scholten et al., 2014; Scholten and Schilder, 2015), diversification strategies (Sheffi and Rice, 2005; Urciuoli et al., 2014), business continuity management systems (Sahebjamnia et al., 2015, Namdar, 2020), distributed power (Sheffi and Rice, 2005), information sharing (Christopher and Peck, 2004; Tang, 2006), unbreakable relationships with the key suppliers (Sheffi and Rice, 2005; Tang, 2006), flexible supply base and multiple sourcing (Chopra and Sodhi, 2004; Johnson et al., 2013), suppliers' risk awareness (Christopher and Peck, 2004), identical plant design/process and facilities (Tang and Tomlin, 2008; Tang, 2006), reduced recovery time through preparedness and anticipation (Sahebjamnia et al., 2015), multiple transportation routes (Fiksel, 2003; Tang, 2006), and multi-modal transportation (Tang, 2006).

Much of the current work on supply chain resilience has primarily addressed the use of mitigation strategies. Such strategies generally aim at reducing the likelihood and/or the impacts of disruptions via developing proactive plans in advance of a disruption, and thus they imply a focus only on absorptive capacity as described by Vugrin et al. (2011). It is important to recognize, however, that resilience behavior also may be associated with a supply chain's adaptive and restorative capacities (i.e. its post-disruption resilience capabilities). Therefore, strategies that can strengthen such capacities also need consideration. However, empirical research in this area has been affected by the lack of a validated measurement model. In this context, Chowdhury and Quaddus (2017) suggested that supply chain managers take proactive approaches towards resilience, design a supply chain that can reduce vulnerabilities, and develop reactive capabilities to respond and recover quickly from vulnerabilities.

The following studies are among the first attempts to develop a comprehensive measurement and assessment tool for analyzing the resilience level of supply chains. They do so by incorporating relevant resilience factors (measurable aspects of the supply chain that can serve as indicators of resilience), resilience strategies, and resilience capacity-making categories into a supply chain resilience assessment framework. Soni et al. (2014) first proposed a model using graph theory that analyzes the enablers of resilience and their 
interrelationships using an Interpretive Structural Modeling approach. The nine enablers are agility, collaboration, visibility, risk management culture, adaptive capability, risk and revenue sharing, trust among players, information sharing, and sustainability. The Soni et al. (2014) ISM methodology ultimately resulted in the creation of a supply chain resilience index (SCRI). In this particular research effort, however, they did not consider the interrelationships among different resilience strategies.

Falasca et al. (2008) proposed a simulation-based framework that incorporates concepts of resilience into the process of supply chain design. The focus of the model was on design considerations concerning the flow of materials within the supply chain, as impacted by disruptive changes in the environment that propagates through the physical infrastructure of the supply chain. Simulation has been proven to be a practical tool to test supply chain responses to different strategies for improving disaster resilience.

Chowdhury and Quaddus (2015) subsequently developed a 0-1 multi-objective optimization model based on a QFD-based methodology. They applied their methodology to three companies in Bangladesh. Their results show that lack of materials (high dependence on imported materials), disruptions in utility supply, increased competition (and hence competitive pressure), impact of economic recession, and reputation loss are the top-most vulnerabilities of the Bangladesh Readymade Garment (RMG) industry. The most preferred resilience strategies to mitigate the vulnerabilities are shown to be: back-up capacity, building relationships with buyers and suppliers, quality control, skill and efficiency development, ICT adoption, demand forecasting, responsiveness to customers, and security system improvement.

More recently, Chowdhury and Quaddus (2017) introduced a new measurement instrument for supply chain resilience. They showed that supply chain resilience can be modeled as a multidimensional and hierarchical construct, consisting of three primary dimensions: proactive capability, reactive capability, and supply chain design quality. Interestingly, however, although their suggested resilience dimensions are in line with Vugrin et al.'s (2011) absorptive and adaptive categories, they also fail to consider the complex interrelationships between the different dimensions.

In a related study, Pournader et al. (2016) argued that as the resilience of the overall SCN depends on the resilience level of individual nodes, it is important to develop a resilience 
metric that can evaluate resilience of supply chains at the overall and node levels. They developed a fuzzy data envelopment analysis (DEA) model to assess the resilience at the individual tiers and the overall SCN. The proposed model accounts for different types of risk in different tiers such as network risks, external risks, and organizational risks and provides four efficiency scores (resilience/risk ratio) for a three-tier supply chain: the upstream, organizational, downstream efficiencies and the overall efficiency. However, they did not consider available resilience strategies in different levels of a SCN in their study. For further information on supply chain resilience, the interested readers are referred to Hosseini et al. (2016) and Hosseini et al. (2019a).

\subsection{Social network analysis}

SNA is a term that emerged from the social sciences and that has become very important in modern sociology. It generically refers to a group of elements and the nature and extent of the connections, relationships, or interactions between those elements. It is important to examine how structural relationships among supply chain partners impact the performance of firms using a network analytic lens (Basole et al., 2018). In addition, according to Akgul et al. (2017), SNA can be used to better understand the collaborative networks in different markets and within supply chains of differing sizes.

In general, SNA aims to describe the interactions between individuals within a group. It thus has been used to characterize friendship structure, disease spread, and communication patterns, along with other applications in economics, geography, history, information science, organizational studies, political science, and development studies. Moreno (1934) conducted one of the first formal social network analyses, and developed a quantitative method called Sociometry that was used to measure social relationships and psychological well-being. Recently, Basole et al. (2018) focused on structural prominence and density and their association with firm operating performance.

SNA provides a theoretical framework for formally studying network factors and properties. It allows researchers to identify important components of a network, measuring patterns of contacts and comparing different networks through a number of standard metrics. Table 1 illustrates the most common used SNA metrics and their definitions. The potential of 


\section{Table 1. A summary of some well-known metrics in SNA}

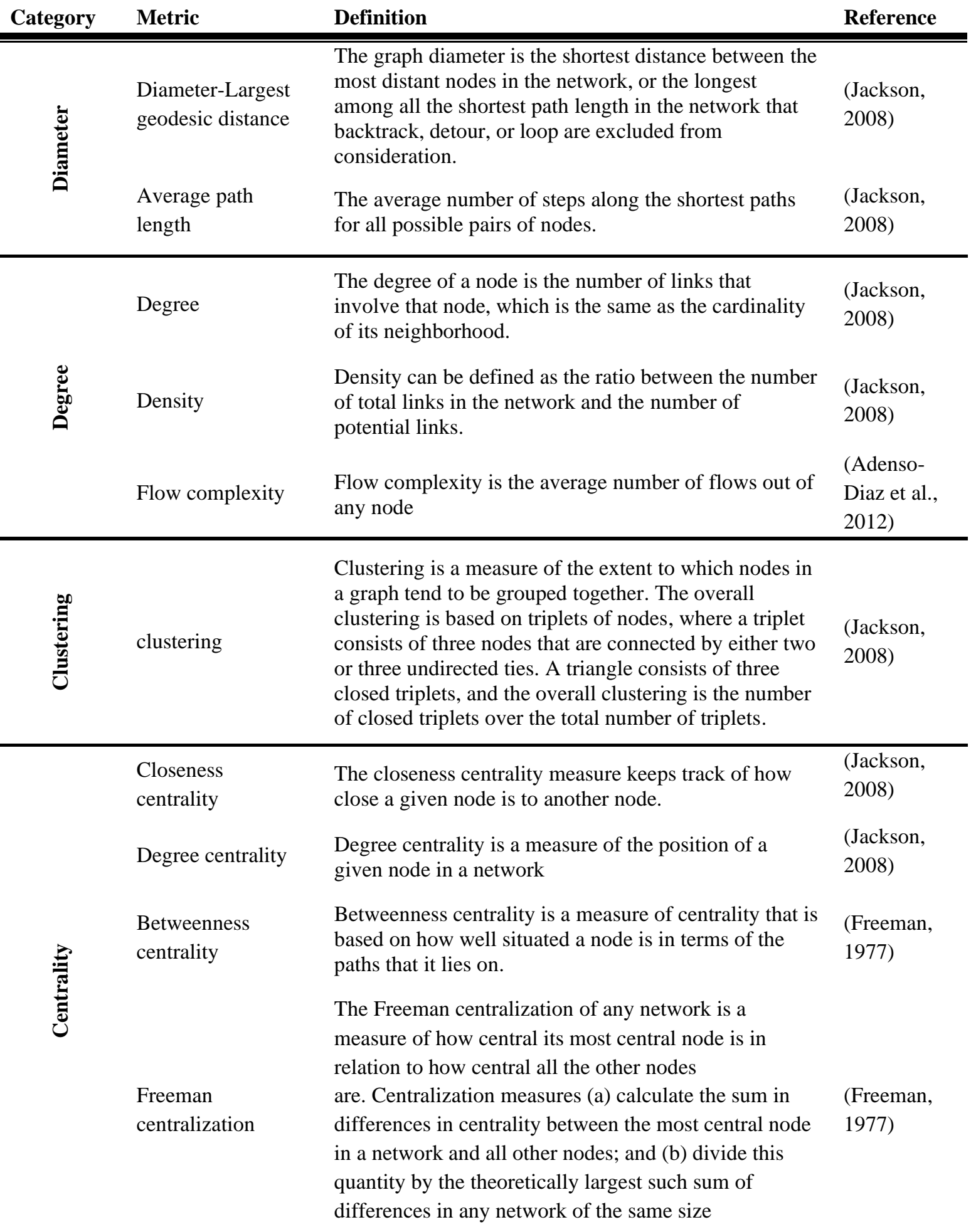


SNA to characterize a SCN structure is of growing interest in supply chain management, although the related literature provides few empirical investigations (Kao et al., 2017).

Supply chain management has traditionally focused on linear relationships between buyers and suppliers. However, while a linear perspective may be useful for planning certain mechanical aspects of transactions between buyers and suppliers, it fails to capture the complexity needed to understand a firm's strategy or behavior, as both depend on a larger SCN in which the firm is embedded (Choi and Kim, 2008). From a network perspective, the relative position of entities with respect to one another influences both strategy and the behavior of the network (Borgatti and Li, 2009). A further example is provided by Zhang et al. (2015), in which they investigated the role of network topology on a transportation system's ability to cope with disruptions. They used six typical graph theoretic network measures to analyze 17 network structures against disruptions and quantified the resilience level of these network structures in terms of throughput, connectivity and compactness. From their numerical experiments, the higher the degree and cyclic metrics (i.e. Connectivity Cyclomatic number $^{2}$ ), the greater the resilience level was. Similarly, Cardoso et al. (2015) considered eleven indicators, some of which were derived from SNA, to assess supply chain resilience. A case study from a European multi-echelon supply chain, including a plant, multiple warehouses, multiple suppliers, multiple disassembly lines, and multiple markets, was used to illustrate the main factors that a manager should consider when designing and planning resilient supply chains.

SNA's ability to quantify the complexity of modern supply chain relationships is justified by a number of studies. Kao et al. (2017) identified those SNA measures that are most closely associated with supply chain efficiency, using archival inter-firm relationship data collected from U.S. public companies in multiple industries. Shao et al. (2018) proposed a data-analytics framework for identifying and classifying nexus suppliers by combining various network centrality measures to capture and reflect different aspects of a supplier's structural importance. The framework discussed by Zhao et al. (2019) allows managers to assess topologies of their SCNs in a range of disruptive situations, thus proactively managing

\footnotetext{
${ }^{2}$ Number of fundamental circuits in the network $(\mu=e-v+G)$, where $e$-number of links in the graph, $v$ number of nodes in the graph, and $G$-number of sub-graphs in the network).
} 
the SCN to understand vulnerabilities of the network before a disruption occurs. Pagano et al. (2018) proposed a framework to assess the resilience of a water distribution system of a city. In this paper, they used the well-known graph theory metrics. The results from the case study demonstrated that the method described in this work, due to its capability to address the multidimensional nature of the system resilience, can help the decision-makers in identifying the main criticalities in both soft and hard infrastructural systems.

\subsection{MADM approach}

MCDM problems can be classified into two main clusters: multi objective decision making (MODM) and multi attribute decision making (MADM). MADM deals with those decision problems involving discrete decision variables and a finite number of alternatives. Among the different MADM techniques, the Analytic Hierarchy Process (AHP) and the Analytic Network Process (ANP) (Saaty, 2001) are the most popular methods applied in the supply chain management area (Tseng, 2009).

MADM techniques use a weighted vector of attributes and a decision matrix indicating the performance of each alternative with respect to each criterion. These individual performance measures are combined using different aggregation functions in order to rank the alternatives and determine the one which is most preferred. This current research effort aims to evaluate the performance of a limited number of alternatives (i.e. the resilience level of several competing SCNs) based on discrete information (i.e. using a number of structural resilience factors inspired by SNA metrics). Thus, this problem can be viewed as an MADM problem.

The Decision-making trial and evaluation laboratory (DEMATEL) method handles and structures complicated causal relationships among variables by using a combination of matrices and/or graphs (Hsu et al. 2013). Compared to other MADM methods like AHP, where factors are considered to be independent, DEMATEL is a method of structural modeling that seeks to characterize interdependence amongst the elements of a system through a causal diagram (Wu et al., 2010). For more information on MADM methods, we refer interested readers to Zavadskas et al. (2014).

\subsection{Gap analysis}


Despite increasing interest in the approach, there are currently only a few applications of SNA in operations and supply chain management. Kim et al. (2011), for example, proposed a theoretical framework that relates the key SNA metrics to supply network constructs so that each supply network is analyzed in terms of both material flow and contractual relationships. Similarly, Kim et al. (2015) showed that node/arc-level disruptions do not necessarily lead to network-level disruptions, and demonstrated the importance of differentiating a node/arc disruption vs. a network disruption. They also indicated that network structure significantly determines the likelihood of disruption. More recently, Li et al. (2019) examined the issue of risk propagation in a supply network and analyzed the impact of different network factors on different types of resilience behavior.

Because of the difficulties in obtaining data, there have been few detailed studies of real life supply chains. Recently, however, researchers are increasingly accepting SNA for its potential to investigate the behavior of a given supply chain against disruptions. For example, Borgatti and Li (2009) claimed that SNA concepts are particularly suitable for studying the network structure of interrelationships in a supply chain and for studying the management of material flow and diffusion of information.

In this study, we develop a comprehensive SCN resilience assessment framework that uses a hybrid MADM methodology as well as several SNA-inspired metrics to investigate the interrelationships between the different components of a SCN. The proposed framework incorporates different resilience strategies for evaluating the overall resilience of a SCN and can be used to study the impacts of applying a resilience improvement action in one part of a $\mathrm{SCN}$ on the overall resilience of that network. More specifically, what is new about our approach is the use of SNA-inspired metrics within a hybrid MADM framework in the context of supply chain resilience at the network level. That is, using the proposed framework, we can calculate and investigate the composite resilience index of some alternative/competing supply chain networks considering the resilience factors, strategies, and capacities, and their interrelationships.

\section{Supply chain resilience assessment framework}

We adopt an SNA-based approach to characterizing the structural complexity of SCNs from the resilience viewpoint, which naturally leads to viewing the resilience assessment process 
as a multi-attribute decision making (MADM) problem. In general, this approach requires defining appropriate evaluation criteria and identifying a number of feasible alternatives, evaluating the performance of each alternative with respect to each criterion, applying a normative multi-criteria analysis method, and finally ranking the alternatives and selecting the best one (Opricovic and Tzeng, 2003). Such an approach requires incorporating expert assessments into the decision process in order to manage the complexity of dealing with multiple factors and multiple criteria. We adopt this approach for our SCN resilience assessment framework.

Applying the framework begins with identifying the measurable SNA-related resilience factors that may be associated with resilient behavior, along with a set of potential resilience strategies that can be implemented to improve the resilience of the SCN. Because of the complexity of the interactions between the multiple resilience factors and resilience strategies, the proposed framework then leverages the knowledge of subject area experts to capture the tradeoffs and interactions between these elements. In particular, it uses a hybrid approach that combines DEMATEL and ANP techniques (Gölcük and Baykasoğlu, 2016).

The DEMATEL technique can help experts evaluate both the strength of the internal dependency (i.e. inner-dependency) among the resilience factors, and the corresponding innerdependency among the resilience strategies (represented by the dotted arrows in Figure 1). The experts are asked to assess the external dependencies (i.e. outer-dependencies) that exist between each strategy and different resilience factors, as well as the outer-dependencies that relate each resilience capacity (i.e. absorptive, adaptive, and restorative resilience capacity) to different strategies (represented by the solid arrows between the three central components in Figure 1). This results in a number of pairwise comparison matrices (PCMs) to obtain either the local weights of resilience factors and strategies with respect to other factors or strategies, or the local weights of resilience strategies with respect to a given resilience capacity, or the weights of different resilience capacities with respect to the overall measure of resilience (i.e. composite resilience index). ANP is then used to create a single super-matrix that combines these PCMs, which is then converted into a limit weighted super-matrix (LWSM) that captures both the direct and indirect influence flows between the different components.

Generally speaking, constructing a composite resilience index (CRI) begins with the weighting and the aggregation of the pre-defined factors (Hatefi and Torabi, 2010). There are 
various MADM techniques in the literature that are associated with creating composite indicators (CIs), such as those which use the common data envelopment analysis (CW-DEA) technique (e.g. Hatefi and Torabi, 2010). Within our hybrid DEMATEL-ANP approach, the elements of the LWSM provide the generalized weights of the different resilience capacities, strategies, and factors (see Figure 1). Once these weights are calculated, the measured values of the SNA-based resilience factors for an actual SCN under consideration can be weighted and combined in order to generate a composite resilience index (CRI) value for that network. Individual CRI values can then be used to rank different SCNs under consideration from a resilience perspective.

It is important to recognize that what differentiates this result from a simple weighted combination of the measured resilience factors is the fact that the final ranking also incorporates the relationship between these resilience factors and the range of possible resilience strategies (Adobor, 2019). Furthermore, the ranking also captures the relationships between resilience strategies and resilience capacities associated with the SCN. It is because of the complexity of such a wide range of relationships that the input of experts, and thus an MADM approach such as ANP, is necessary for assessing the relationships and for quantifying their relative contributions by combining a set of experts' assessments (Bonyani et al., 2019).

We summarize the steps of the proposed hybrid DEMATEL-ANP approach below, while referring the reader to the Supplementary material for a detailed discussion of Step 3.

Step 1: Identify the resilience factors and resilience strategies

Step 2: Use subjective judgements of experts to evaluate the inner- and outerdependencies between the resilience capacities, factors, and strategies using the DEMATEL method

Step 3: Calculate the relative weights for the capacities, strategies, and factors using the ANP method (details provided in the Supplementary material)

Step 4: Use SNA-inspired measures to calculate the values of competing supply chain networks' resilience factors

Step 5: Combine the resilience factors' values with the weights to generate the Composite Resilience Index scores for the competing SCNs 


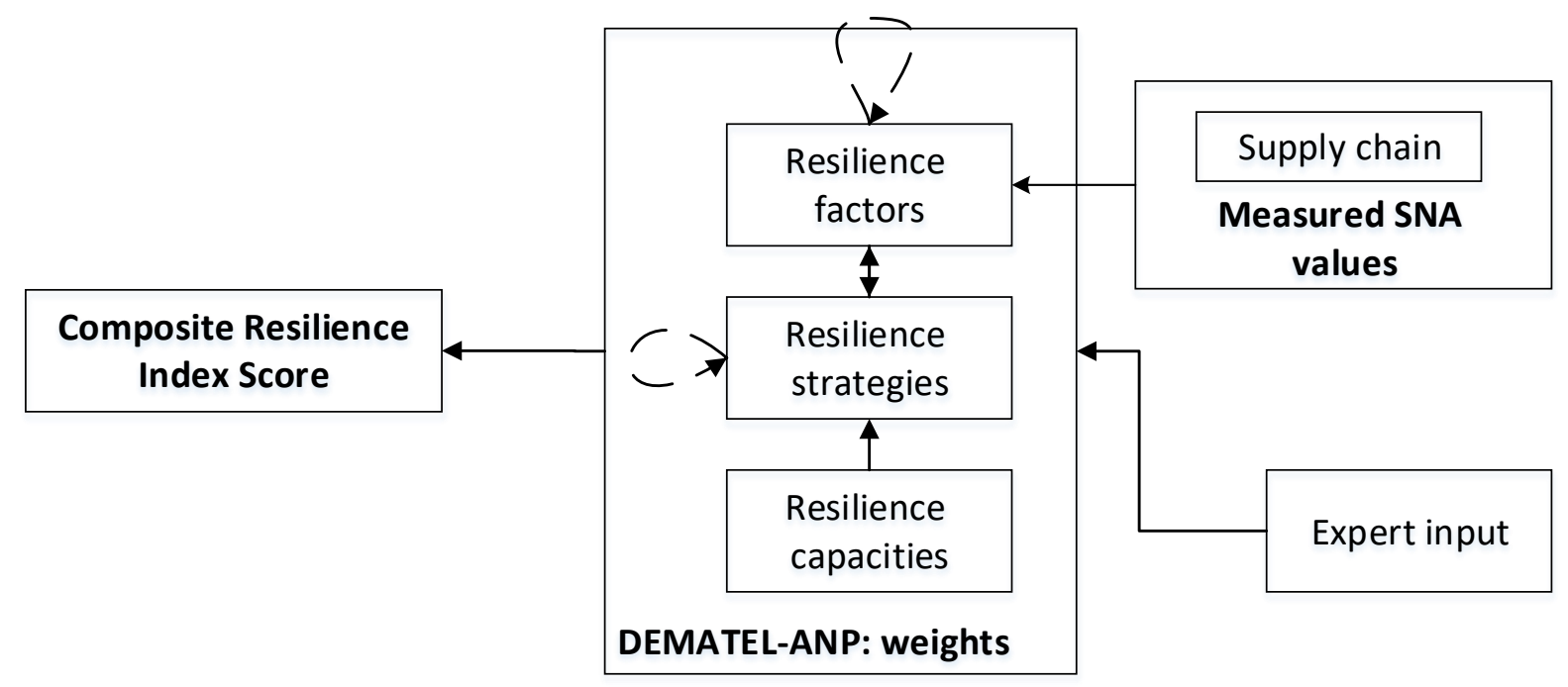

Figure 1. The resilience assessment framework

The following discussion provides more details about the types of resilience strategies and resilience factors that might be considered within the process above, in order to clarify the type of information available to the experts as they participate in the hybrid DEMATEL-ANP process. The case study in the following section then elaborates further on implementing the proposed method within the overall SCN resilience assessment framework.

\subsection{Supply chain resilience strategies}

Namdar et al. (2020) proposed a new quantitative framework for the business continuityinspired resilient SCN design problem. They categorized the resilience strategies in four classes including Anticipation, Preparation, Robustness, and Recovery. We first provide examples of specific supply chain resilience strategies that were chosen among those previously discussed by Namdar et al. (2020). These strategies were classified into four categories relating to the different echelons in a supply chain, as given below. It is important to note that these particular strategies were chosen simply to help illustrate the proposed resilience assessment framework, and that there are many other combinations (or subsets) of supply chain resilience strategies that could have been considered instead, in order to illustrate other factors of supply chain resilience. When applying the SCN resilience assessment framework, decision makers may include other relevant resilience strategies based on factors of their SCN and industry. 


\subsubsection{Strategies affecting the whole supply chain}

Collaborative relationships among the supply chain partners (CRSCP): Cooperative relationships among supply chain partners are considered to be one of the key factors that can increase the resilience of the whole supply chain. The purpose of such cooperation is to share resources, expertise, knowledge, and information between the supply chain's facilities. In order to reduce or effectively manage supply chain risks, organizations need to establish communication and collaboration among different parties, and particularly the key partners (Christopher and Peck, 2004; Sheffi and Rice, 2005; Tang, 2006).

Diversification strategies (DS): The literature demonstrates that using a diversification (i.e. redundancy) strategy in selecting the supply base and/or other facilities (e.g. manufacturing and distribution sites) can reduce the risk of supply chain disruptions significantly. However, such strategies are often very expensive due to their high implementation cost (Sheffi and Rice, 2005).

Establishment of supply chain business continuity management systems (SCBCMS): It is almost impossible to predict a disruption's nature, time, and extent. Therefore, a supply chain needs to be proactively equipped with a business continuity management system (BCMS) to protect itself against the outcomes of disruptive events (Sahebjamnia et al., 2015). Sahebjamnia, Torabi, and Mansouri (2015) proposed a novel framework for integrated business continuity and disaster recovery planning for efficient and effective resumption and recovery of critical disrupted operations. Christopher and Peck (2004) also argued that the establishment of supply chain continuity teams should go beyond the level of organizational risk management and address business continuity management across the whole supply chain.

Distributed power (DP): Distributing power among supply chain partners means creating and empowering partners to make fast decisions in emergency situations, and thus enabling each of them to reduce the impact of disruptions. Without the need to wait for instructions from other key partners, each participant can make suitable decisions to reduce the disruption's effects (Sheffi and Rice, 2005).

Information sharing (IS): One of the most important strategies for effective management of a 
supply chain is information sharing among the supply chain partners. Information sharing increases the flexibility and responsiveness of each supply chain member, and enables them either to avoid or to reduce the risk of a disruption (Christopher and Peck, 2004; Sheffi and Rice, 2005; Tang, 2006).

\subsubsection{Strategies affecting the supply echelon}

Unbreakable relationships with the key suppliers (URKS): The business continuity of a supply chain is often highly dependent on a number of key suppliers. Therefore, a deep and close relationship with those suppliers can enhance the resilience level of the whole supply chain. This kind of relationship can help to manage the potential supply risks in the supply chain and it enables the suppliers to overcome the interruptions more effectively (Tang, 2006).

Flexible supply base and multiple sourcing (FSBMS): This strategy creates a flexible supply chain, as flexibility enables a firm to reallocate available supply sources quickly and smoothly in response to a disruptive event (Chopra and Sodhi, 2004).

Suppliers' risk awareness (SRA): Suppliers' risk awareness is one of the most important factors in supplier selection. The predicament of Land Rover, a subsidiary of Ford, in January 2002 illustrates this point. Land Rover's production was endangered by the collapse of its supplier. That supply chain was actually at risk because of the supplier's failure, not directly due to a problem between the supplier and its customers.

\subsubsection{Strategies affecting the production echelon}

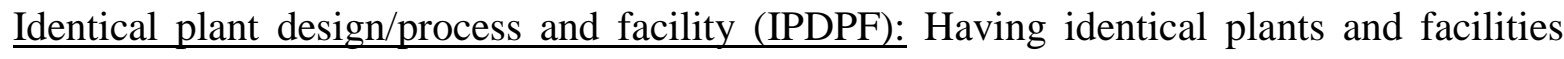
increases flexibility in the face of disruptions, especially those disruptions related to changes in demand. This flexibility means that products can be moved between supply partners to cope with changes in demands(Tang and Tomlin, 2008; Tang, 2006).

Reduced Recovery Time by Preparedness and Anticipation (RRTPA): Appropriate preparedness for responding to disruptions requires proper contingency planning and the use of available resources during the pre-disruption phase, through the design and implementation of effective business continuity plans (BCPs) (Sahebjamnia et al., 2015). This includes conducting business impact analysis (BIA), risk assessment (RA) and business continuity 
planning. These management efforts increase the supply chain's preparedness (i.e. readiness) level against disruptions, which ultimately leads to reducing both the impact of damages and the length of time needed to recover (Pettit et al., 2013; Tang, 2006).

\subsubsection{Strategies affecting the distribution echelon}

Multiple transportation routes (MTR): In order to cope with transportation related disruptions and ensure the continuity of material flows through the supply chain in any circumstances, many companies consider alternative transportation routes (Fiksel, 2003; Tang, 2006).

Multi-modal transportation (MMT): A multi-modal transport system can also be very effective in the face of a transportation mode's disruption (Tang, 2006).

It should be mentioned that no company or supply chain can afford to adopt all of these strategies. Different supply chain conditions affect the appropriateness of the various strategies. Managers must understand the advantages and disadvantages of the various resilience strategies, and in what circumstances they could be beneficial. Managers should also consider the composition of risk management teams, in terms of functions and orientations represented, to assess and manage global supply chain risks.

\subsection{Quantitative resilience factors}

Measuring resilience in supply chains is a problematic task because the interrelationships among supply chain resilience strategies and factors are difficult to understand and manage. Nevertheless, in this paper, we aim to conduct a comprehensive quantitative supply chain resilience analysis and investigate the resilience behavior of some competing supply chains against potential disruptions. For doing so, eleven different network factors are selected and adopted from the social network analysis literature and supply chain resilience literature and applied to interpreting different aspects of the interrelationships between supply chain resilience strategies and factors. These factors include: network complexity, source criticality, supplier complexity, density, node criticality, flow reliability, flow complexity, and network centralization.

We also define some new supply chain design factors, namely "overall clustering", “overall closeness centrality”, “overall degree centrality”, "overall betweenness centrality”, "overall flow complexity", and "overall degree centrality for source nodes" to make this 
analysis more comprehensive. The following discussion presents the quantitative metrics by which we may measure each of these network factors.

Network complexity: Birkie et al. (2017) showed that complexity of SCNs has a moderating impact on resilience capabilities and performance after disruptions. SCN complexity can be represented by the network's size, which is determined by the number of nodes in the network:

size of the network = total number of nodes in the network

Source criticality: Source criticality, or the crucial importance of the source nodes in the supply chain, is a category that includes the following factors.

Average path length in the network: The average path length is defined as the average number of steps along the shortest paths for all likely pairs of nodes in the network. It is also a measure of the efficiency of information or mass transport on a network.

Diameter: Diameter in social network analysis is the largest number of nodes which must be traversed in order to travel from one node to another when any backtrack, detour, or loop are excluded from consideration (i.e. the longest geodesic)

$$
\text { Diameter }=\max _{u . v} d(u . v)
$$

where $d(u . v)$ is the distance between node $u$ and node $v$.

Overall closeness centrality of source nodes: Concern with centrality in social network analysis stems from the idea that a person who is close to others will have access to more information, has more power, has higher status or has greater influence than others (Freeman et al., 1991). Closeness centrality keeps track of how close a given node is to other nodes and can be measured as follows (Jackson, 2008):

$$
\text { Closeness centrality of node } i=\frac{n-1}{\sum_{j \neq i} l(i . j)}
$$

where $l(i, j)$ is the number of steps in the shortest path between node $i$ and $j$. While $\mathrm{n}$ is the total number of nodes in the supply chain. Consequently, overall closeness centrality of source nodes can be defined as the summation of closeness centrality of source nodes:

$$
\text { Overall closeness centrality of source nodes }=\sum_{i \in S} \frac{n-1}{\sum_{j \neq i} l(i . j)}
$$


Based on our observations, the average path length in the network, diameter, and the overall closeness centrality are the most common factors that are used in designing an economic supply chain in the literature. However, these factors are not specific in a supply network, while their factors are very important in the suppliers' echelon. So, in this paper, we use these factors to measure the source criticality.

Overall degree centrality for source nodes: Degree centralization originated from graph theory simply measures the position of a given node in a network via its degree. The degree of a node is the number of edges which it touches. The degree centrality of a node is simply defined as: $d_{i}(g) / n-1$ where $d_{i}(g)$ is the degree of node $i$ and $n$ defines the total number of nodes in the graph (Jackson, 2008). So, overall degree centrality for source nodes is defined as follows:

$$
\text { Overall degree centrality for source nodes }=\sum_{i \in S} \frac{d_{i}(g)}{n-1}
$$

The overall degree centrality for source nodes can enhance the adaptive and restorative capacities.

Supplier complexity: Some researchers have defined supplier complexity as the percentage of nodes that act as supplier (Adenso-Diaz et al., 2012; Wang et al., 2005). So,

$$
\text { Supplier complexity }=\frac{\text { the total number of source nodes }}{\text { the total number of nodes }}
$$

As we can see in Eq. 6 source nodes are the nodes that supply the network and have no demands

Density: According to the literature of social network analysis and graph theory, density can be defined as the ratio between the number of total links in the network and the number of potential links.

$$
\text { Density }=\frac{\text { the number of total links in the network }}{\text { the number of potential links }}
$$

Noteworthy, density is calculated on all nodes but "overall degree centrality of source nodes" is calculated only on source nodes. 
Node criticality: This factor calculates the criticality of all nodes in the network. Since in a supply chain suppliers play a more important role (as well as in disruptions), in this paper we discuss them separately (see source criticality). Node criticality includes the following factors: Overall clustering: In the social network analysis literature, the clustering coefficient is a measure of the extent to which nodes in a graph tend to cluster together (Jackson 2008). The overall clustering is based on the triplets of nodes. In other words, "overall clustering can be measured by looking across all situations where two links both emanate from the same node, so for instance $i-j$ and $i-k$ edges both involve node $i$, and ask what proportion of the time it is that $j-k$ is then also in the network".

$$
\text { Overall clustering }=\frac{\sum_{i} \#\left\{j k \in g \mid k \neq j, j \in N_{i}(g), k \in N_{i}(g)\right\}}{\sum_{i} \#\left\{j k \mid k \neq j, j \in N_{i}(g), k \in N_{i}(g)\right\}}
$$

The overall clustering factor in a supply chain can measure the node criticality in such a way the greater the overall clustering coefficient is, the fewer the number of critical nodes in the network would be.

Percentage of critical nodes: A node is considered to be critical when the sum of its inbound and outbound links (i.e. its degree) is higher than a determined target value provided by the top manager (Cardoso et al., 2015):

$$
\text { Percentage of critical nodes }=\frac{\# \text { of critical nodes }}{\# \text { of total nodes }}
$$

Flow reliability: Flow reliability can be defined as the mean reliability of flows (i.e. reliability of links and roads between entities) (Adenso-Diaz et al., 2012). Betweenness centrality of a node is a key centrality indicator in the social network analysis that is equal to the number of shortest paths from all nodes to all others that pass through that node. A node with high betweenness centrality has a large influence on transferring flows through the network. Betweenness centrality of node $k$ can be defined as follows (Jackson, 2008):

$$
\text { Betweenness centrality of node } k=\sum_{i j: i \neq j . k \notin\{i . j\}} \frac{P_{k}(i j) / P(i j)}{(n-1)(n-2) / 2}
$$

where $P(i j)$ denotes the number of shortest paths connecting node $i$ to node $j, P_{k}(i j)$ 
Table 2. Summary of the resilience factors

\begin{tabular}{|c|c|c|c|}
\hline Num. & factor & Abbreviation & How to measure \\
\hline 1 & Size of the network & SON & total number of nodes in the network \\
\hline \multirow{4}{*}{2} & $\begin{array}{l}\text { Average path length in } \\
\text { the network }\end{array}$ & APLN & $\begin{array}{l}\text { average number of steps along } \\
\text { the shortest paths for all likely pairs } \\
\text { of network nodes }\end{array}$ \\
\hline & Diameter & $D I$ & $\max _{u, v} d(u, v)$ \\
\hline & $\begin{array}{l}\text { Overall closeness } \\
\text { centrality of source nodes }\end{array}$ & OCCSN & $\sum_{i \in S} \frac{n-1}{\sum_{j \neq i} l(i, j)}$ \\
\hline & $\begin{array}{l}\text { Overall degree centrality } \\
\text { for source nodes }\end{array}$ & ODCSN & $\sum_{i \in S} \frac{d_{i}(g)}{n-1}$ \\
\hline 3 & $\begin{array}{l}\text { The proportion of } \\
\text { suppliers }\end{array}$ & PS & $\frac{\text { the total number of source nodes }}{\text { the total number of nodes }}$ \\
\hline 4 & Density & $\mathrm{D}$ & $\frac{\text { the number of total links in the network }}{\text { the number of potential links }}$ \\
\hline \multirow[t]{2}{*}{5} & Overall clustering & OC & $\frac{\sum_{i}\left\{j k \in g \mid k \neq j, j \in N_{i}(g), k \in N_{i}(g)\right\}}{\sum_{i} \#\left\{j k \mid k \neq j, j \in N_{i}(g), k \in N_{i}(g)\right\}}$ \\
\hline & $\begin{array}{l}\text { Percentage of critical } \\
\text { nodes }\end{array}$ & $\mathrm{PCN}$ & $\frac{\# \text { of critical nodes }}{\# \text { of nodes }}$ \\
\hline 6 & $\begin{array}{l}\text { Overall betweenness } \\
\text { centrality of nodes }\end{array}$ & OBCN & $\sum_{k} \sum_{i j: i \neq j, k \notin\{i, j\}} \frac{\frac{P_{k}(i j)}{P(i j)}}{\frac{(n-1)(n-2)}{2}}$ \\
\hline 7 & Overall flow complexity & OFC & $\sum_{i} \frac{d_{i}^{+}(g)}{n-1}$ \\
\hline 8 & Freeman centralization & $\mathrm{FC}$ & $\frac{\sum_{i}\left(d_{i}^{*}(g)-d_{i}(g)\right)}{\max \left(\sum_{i}\left(d_{i}^{*}(g)-d_{i}(g)\right)\right.}$ \\
\hline
\end{tabular}

Denotes the number of these paths that node $k$ lies on and $n$ denotes the total number of nodes. In this way, the overall betweenness centrality of nodes can be defined as:

$$
\text { Overall betweenness centrality of nodes }=\sum_{k} \sum_{i j: i \neq j . k \notin\{i . j\}} \frac{P_{k}(i j) / P(i j)}{(n-1)(n-2) / 2}
$$

Overall flow complexity: Adenso-Diaz et al. (2012) defined flow complexity as the average number of flows out of any node. In the social network analysis literature, flow complexity 
can be defined as the average out degree of nodes. Kim et al. (2011) mentioned this factor as out-degree centrality. So, we develop overall flow complexity as follows:

$$
\text { Overall flow complexity }=\sum_{i} \frac{d_{i}^{+}(g)}{n-1}
$$

where $d_{i}^{+}(g)$ is out degree of node $i$ and $n$ is the total number of nodes in the supply chain.

Network centralization: The network centralization indicators are based on the number and intensity of the flows adjacent to each node (Cardoso et al., 2015). The freeman centralization of a network is a measure of how central its most central node is in relation to how central all the other nodes are (Freeman 1979). According to the above definition, the higher a given network's freeman centralization, the more importance of a central node would. The freeman centralization can be measured as below:

$$
\text { Freeman centralization }=C_{x}=\frac{\sum_{i}\left(d_{i}^{*}(g)-d_{i}(g)\right)}{\max \left(\sum_{i}\left(d_{i}^{*}(g)-d_{i}(g)\right)\right.}
$$

where $d_{i}^{*}(g)$ is the maximum degree centrality in the network.

\section{Case study: Unveiling the structure of Honda, Acura, and Daimler Chrysler's supply chains}

Any MADM based method requires rich and detailed data for practical application and thus data collection is a major limitation in conducting a thorough analysis. In this section, therefore, the performance of the suggested resilience factors and the proposed hybrid MADM approach (i.e. the hybrid DEMATEL-ANP) is investigated with respect to three automotive supply chains whose required data has been borrowed from the literature. Choi and Hong (2002) and Kim et al. (2011) reported three automobile supply chains, including the three center console assemblers of Honda Accord, Acura CT/TL, and Daimler Chrysler (DCX) Grand Cherokee, and derived some observations regarding the behavioral factors of these supply chains based on their networks' topologies.

According to Choi and Hong (2002), all data were gathered through visiting the related companies where the data came primarily from three sources including semi-structured 
interviews, relevant documents (e.g. bill-of-materials (BOMs), vendor agreements, pre-source package forms (PSFs)), and direct observations (via conducting plants' tours). Figures 3 to 5 illustrate the material flow supply chains for the Accord, the Acura CT/TL, and the Daimler Chrysler (DCX) Grand Cherokee, respectively.

In the Accord's material flow supply chain for the center console assembly (see Figure 3), CVT and JFC are top tier suppliers. Considering other second-tier and third-tier suppliers selected by Honda, all together there are 28 network entities (i.e. suppliers) in this supply chain. According to Figure 4, in the material flow supply chain for the Acura CT/TL's center console assembly, Intek is the top tier supplier and the directed sourcing strategy is used at the other tiers. Altogether, there are 34 entities in this supply chain. Figure 5 illustrates the material flow supply chain for the DCX Grand Cherokee's center console assembly. In this network, Textron plays a crucial role as the sole top tier supplier by integrating other parts' suppliers and sub-assemblers. Altogether, there are 27 network entities in this supply chain.

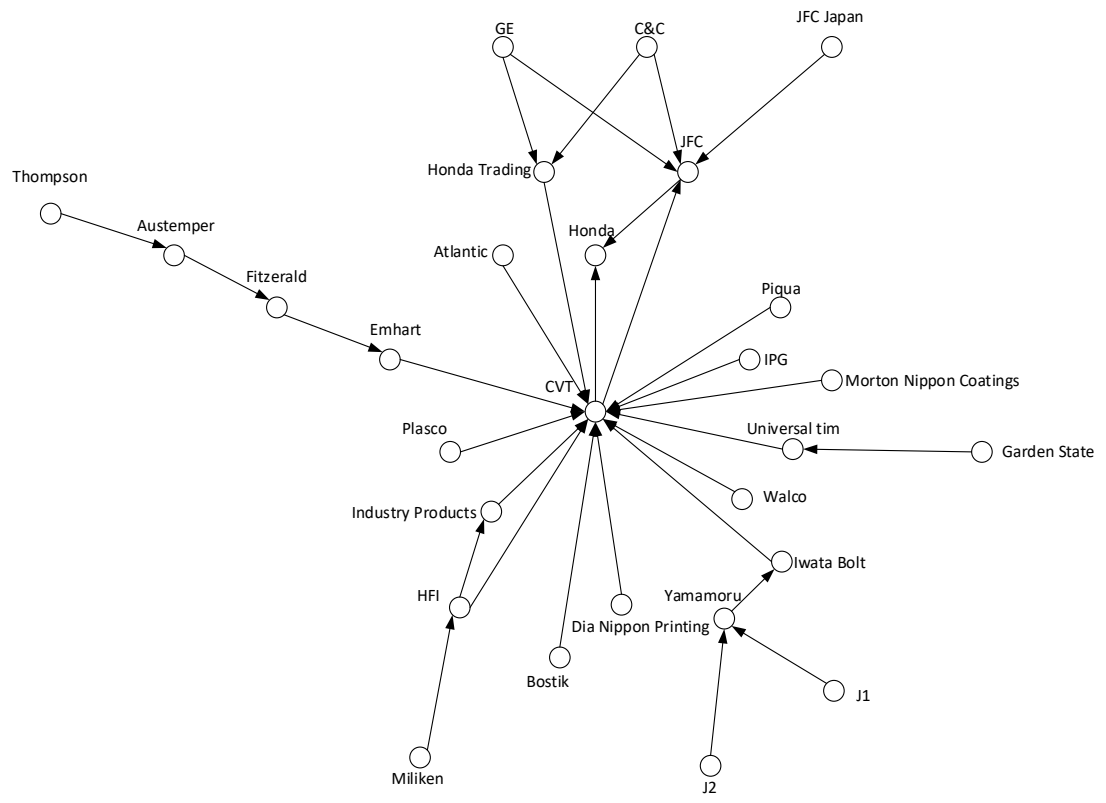

Figure 3. Accord's material flow supply chain (adopted from Kim et al., 2011) 


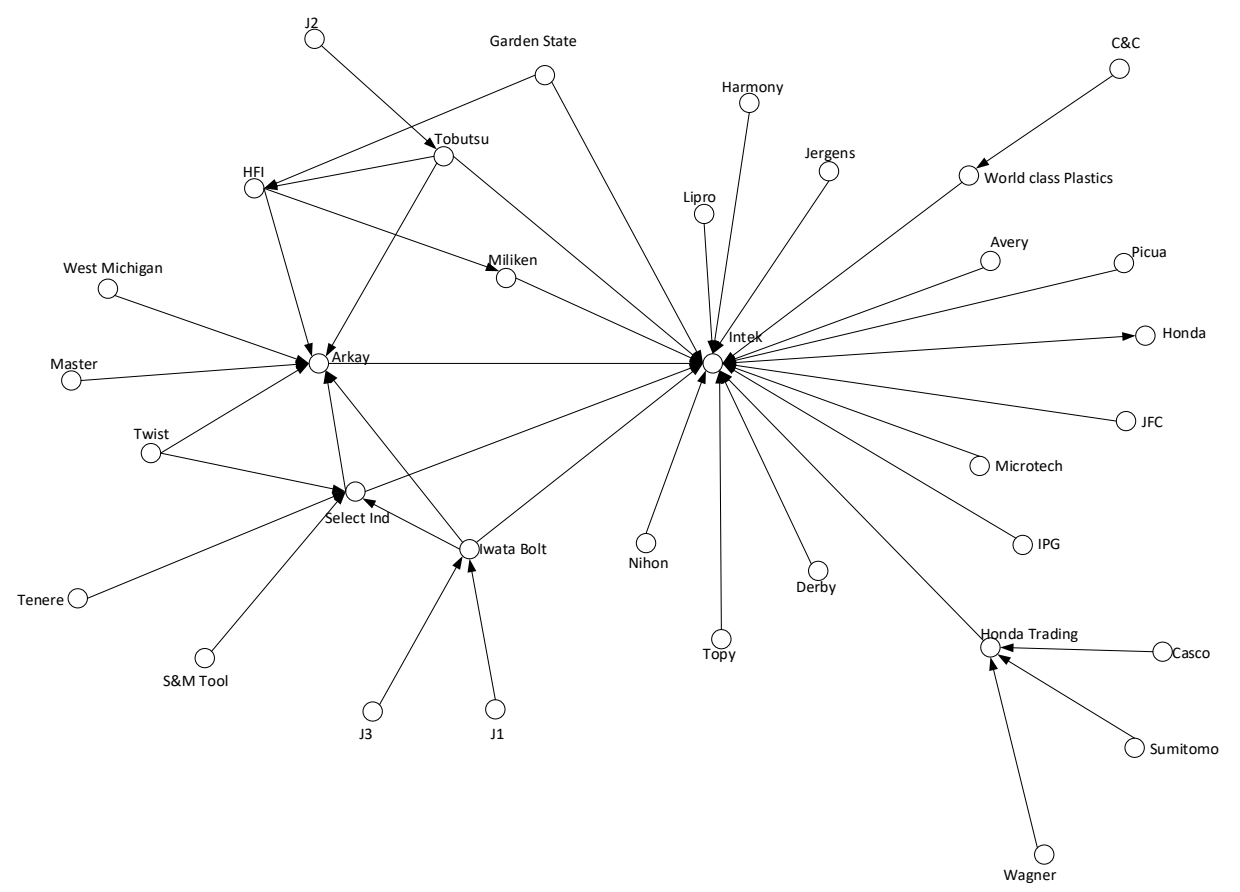

Figure 4. Acura CT/TL's material flow supply chain (adopted from Kim et al., 2011)

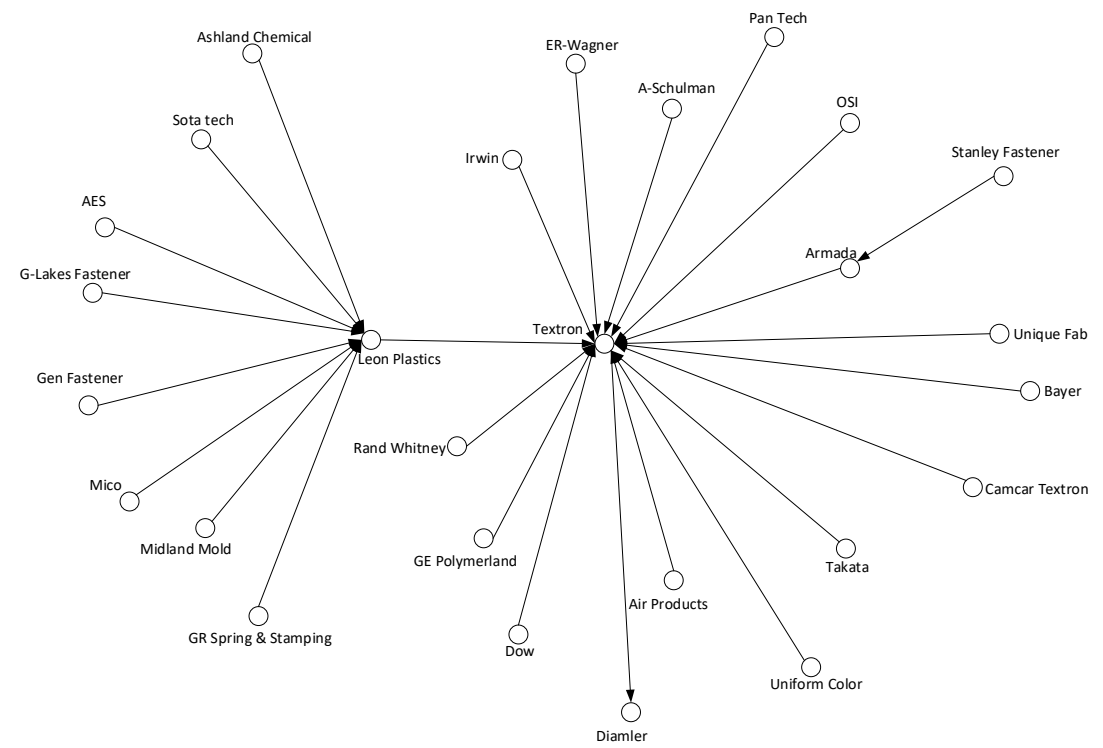

Figure 5. DCX Grand Cherokee's material flow supply chain (adopted from Kim et al., 2011) 
Table 3. Calculated resilience factors for the three supply chains

\begin{tabular}{|c|c|c|c|c|}
\hline Num. & Resilience factors & Accord & Acura CT/TL & $\begin{array}{l}\text { DCX Grand } \\
\text { Cherokee }\end{array}$ \\
\hline 1 & Size of the network (SON) & 28 & 34 & 27 \\
\hline \multirow{4}{*}{2} & Average path length in the network (APLN) & 2.902116 & 2.516934 & 2.381766 \\
\hline & Diameter (DI) & 7 & 4 & 4 \\
\hline & $\begin{array}{l}\text { Overall closeness centrality of source nodes } \\
\text { (OCCSN) }\end{array}$ & 0.197609 & 0.286749 & 0.361324 \\
\hline & $\begin{array}{l}\text { Overall degree centrality for source nodes } \\
\text { (ODCSN) }\end{array}$ & 0.642857 & 0.882353 & 0.851852 \\
\hline 3 & The proportion of suppliers (PS) & 0.571429 & 0.735294 & 0.851852 \\
\hline 4 & Density (D) & 0.082011 & 0.073084 & 0.074074 \\
\hline \multirow{2}{*}{5} & Overall clustering (OC) & 0.013889 & 0.027888 & 0 \\
\hline & Percentage of critical nodes (PCN) & 0.071429 & 0.205882 & 0.074074 \\
\hline 6 & $\begin{array}{l}\text { Overall betweenness centrality of nodes } \\
(\mathrm{OBCN})\end{array}$ & 3.764550 & 2.756090 & 2.763533 \\
\hline 7 & Overall flow complexity (OFC) & 2.296296 & 2.484848 & 2 \\
\hline 8 & Freeman centralization $(\mathrm{FC})$ & 25.733333 & 31.473684 & 25.437500 \\
\hline
\end{tabular}

The resilience factor values for each of these three supply chains were all calculated in MATLAB, and Dijkstra's algorithm was specifically used to derive the overall betweenness, centrality of source nodes, the average path length, the diameter, and the overall closeness centrality of source nodes (Bondy and Murty, 1976; Dijkstra, 1959; Jackson, 2008). The results of these calculations are shown in Table 3.

The hybrid DEMATEL-ANP approach was then conducted to explore the inner dependencies among the elements of the third cluster (i.e. the resilience strategies) and the fourth cluster (i.e. the resilience factors) of the decision network, respectively, using an expert panel consisting of nine experts (including the sales managers, systems and ERP directors, logistics and production planning managers, as well as some academic experts) from wellknown automobile companies in Iran. The resulting weights were then combined with the measured factor values in Table 3 to generate a CRI value for each SCN. We avoid presenting 
Table 4. The global weights for the competing supply chains

\begin{tabular}{l|l|l} 
Competing supply chains & CRI & Rank \\
\hline \hline Accord & 0.324407 & 2 \\
Acura CT/TL & 0.35207 & 1 \\
DCX Grand Cherokee & 0.323523 & 3
\end{tabular}

Table 5. The global weights with respect to each category of resilience making capacities

\begin{tabular}{l|l|l|l|l|l|l}
$\begin{array}{l}\text { Competing } \\
\text { supply chains }\end{array}$ & Absorptive & $\begin{array}{l}\text { Rank in } \\
\text { Absorptive }\end{array}$ & Adaptive & $\begin{array}{l}\text { Rank in } \\
\text { Adaptive }\end{array}$ & Restorative & $\begin{array}{l}\text { Rank in } \\
\text { Restorative }\end{array}$ \\
\hline \hline Accord & 0.325847 & 2 & 0.324186 & 3 & 0.325498475 & 2 \\
Acura CT/TL & 0.356289 & 1 & 0.349564 & 1 & 0.348220293 & 1 \\
$\begin{array}{l}\text { DCX Grand } \\
\text { Cherokee }\end{array}$ & 0.317864 & 3 & 0.32625 & 2 & 0.32628123 & 3
\end{tabular}

the entire limit super-matrix here and simply show the global weights for the competing supply chains (i.e. their CRIs) in Table 4, as well as their weights in each resilience making capacity category in Table 5.

As we can see in Tables 4 and 5, the multi-attribute resilience assessment framework provides the ability to quantify resilience by using a single numerical index (CRI). This will help decision makers choose various risk mitigation strategies more effectively. The framework also provides flexibility in choosing resilience factors and resilience strategies, and thus in identifying the various relationships and interrelationships within a supply chain, with the result that it can be applied to a variety of different SCNs.

\section{Discussion}

In the past decade, the critical infrastructures and essential service providers that enable supply chains to thrive and grow have become increasingly interconnected and interdependent at both local and global scales. Supply chain managers have begun to focus on these interdependencies and on the vital connections between the supply chain and these infrastructures, in order to implement resilience capacity making strategies that can prevent or lessen the impacts of potential disruptions. A disruption that strikes one infrastructure can cascade to other infrastructures (such as a disruption suffered by Arkay, in Acura CT/TL's supply chain, that subsequently impacts Intek). By understanding the resilience making 
capacity categories, resilience strategies, and resilience factors discussed above, as well as their interrelationships in a supply chain, the decision makers can plan for implementing more effective resilience improvement actions. In particular, this requires interpreting the resilience factors in the context of the factors of the actual supply chains being analyzed, with their specific flows and relationships and node types, and in the context of strategies that are relevant to that type of supply chain. With this in mind, we provide some observations below.

Observation 1 (O1). Adding additional nodes may not increase the resilience of a supply chain.

Adding additional nodes adds resilience only when those additional nodes supply similar products with other suppliers. If the additional node is the sole supplier for a component, adding it will increase the vulnerability of the network. As can be seen from Table 6, Acura CT/TL, DCX Grand Cherokee, and Accord are ranked from first to third place in terms of their SON (size of network) resilience factor values, whereas Accord is in second place in terms of the overall composite resilience index value. Therefore, it can be concluded than an increase in the number of nodes (i.e. facilities) in a supply chain does not necessarily lead to an increase in CRI value.

Table 6. Competing supply chains' ranking in terms of SON and CRI

\begin{tabular}{l|l|l|l|l}
$\begin{array}{l}\text { Competing supply } \\
\text { chains }\end{array}$ & CRI & $\begin{array}{l}\text { Rank in } \\
\text { CRI }\end{array}$ & SON & $\begin{array}{l}\text { Rank in } \\
\text { SON }\end{array}$ \\
\hline \hline Accord & 0.324407 & 2 & 0.325858 & 3 \\
Acura CT/TL & 0.35207 & 1 & 0.34613 & 1 \\
$\begin{array}{l}\text { DCX Grand } \\
\text { Cherokee }\end{array}$ & 0.323523 & 3 & 0.328012 & 2
\end{tabular}

Observation 2 (O2). Overall clustering plays a critical role in the resilience level of supply chains.

The overall clustering reflects the overall pattern of connectedness in a network. As we can observe from Table 7, there is a similar ranking for competing supply chains for both the overall clustering and the composite resilience index, which indicates a positive correlation. 
In our expert panel's opinion, the higher the overall clustering degree, the lower the node criticality factor in a supply chain would be. To explain this, consider the nodes as the supply facilities and the ties among them as the flow routes among the facilities in a supply chain. In the case of a disruption happening in a facility, if it belongs to a particular cluster in the network then the decision makers can use the capacity of other facilities within this cluster to maintain the flow of goods and avoid disrupting the whole supply chain. For example, consider Figure $6 \mathrm{a}$ and Figure $6 \mathrm{~b}$. In the scenario represented by Figure $6 \mathrm{a}$, the first facility is responsible for producing and transferring component $\mathrm{A}$ to the second and third facilities. The second facility in Figure 6a produces component B, but it also follows the resilience strategy of inventory prepositioning and contracts with a backup supplier for component A. In contrast, in Figure 6b, the first and second facilities are responsible for producing and transferring components A and B to the third facility, respectively, and there are no resilience strategies in place.

Table 7. Competing supply chains' ranking in terms of OC and CRI

\begin{tabular}{l|l|l|l|l}
$\begin{array}{l}\text { Competing supply } \\
\text { chains }\end{array}$ & CRI & $\begin{array}{l}\text { Rank in } \\
\text { CRI }\end{array}$ & OC & $\begin{array}{l}\text { Rank in } \\
\text { OC }\end{array}$ \\
\hline \hline Accord & 0.324407 & 2 & 0.332122 & 2 \\
Acura CT/TL & 0.35207 & 1 & 0.417961 & 1 \\
$\begin{array}{l}\text { DCX Grand } \\
\text { Cherokee }\end{array}$ & 0.323523 & 3 & 0.249917 & 3
\end{tabular}

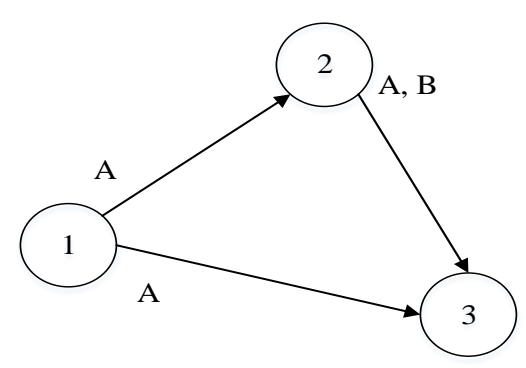

a

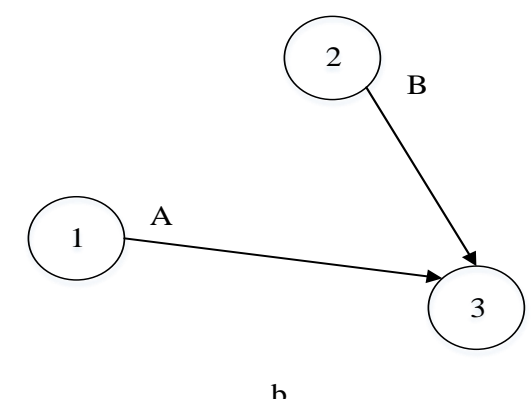

b

Figure 6: An illustrative example of clustering rule in a supply network 
In the case of a disruption to the first facility, the whole supply chain can perform normally in the situation given by Figure $6 \mathrm{a}$, because the first facility is in a cluster in the network. In Figure 6b, however, the overall supply chain's operations are disrupted.

Observation 3 (O3). The suppliers' positions and the way that they are linked up in the network play vital roles in calculating the CRI.

As mentioned before, the interdependence of global suppliers and infrastructures has become increasingly important from the perspective of enabling supply chain resilience. The presented case study shows that the linkages and connectedness among a supply chain's entities affect its resilience level. By understanding the adaptive and restorative capacities (e.g the locations of the suppliers), we can conclude that only adopting proactive and absorptive strategies (e.g. making the suppliers more reliable through establishing business continuity plans) may not be sufficient to enhance the resilience level of the whole supply chain.

As Table 4 indicates, Acura CT/TL is the most resilient supply chain among the three competing supply chains according to the calculated CRIs derived from the proposed hybrid DEMATEL-ANP methodology. In Table 4, Acura's supply chain shows a comparatively high level of performance against disruptions compared to the Accord and DCX supply chains. In particular, Acura's supply chain has a relatively high score regarding the overall clustering, which plays a crucial role in the resilience of the whole supply chain. A supply chain with a high degree of overall clustering would be expected to react somewhat confidently in the case of an entity or link disruption, since the network's operations will be supported by other nodes and links through which the materials could be temporarily moved.

Other important factors in support of supply chains' resilience are the average path length and the diameter. Based on these two factors in particular, Acura outperforms the other supply chains overall because there are fewer steps required to move the materials through Acura's supply network. This also indicates that Acura's network can operate more efficiently (e.g. with lower lead times) as it imposes less managerial attention on the firms in a central position.

In summary, the use of SNA indicators to assess the resilience level of a SCN can be helpful when the top managers need to evaluate the post-disruption performance of a large SCN in real time, or when they need to compare the post-disruption performance of some 
possible/competing topological designs of a SCN. This is because it is generally much faster to compute SNA metrics than to implement an optimization routine to find an optimal solution (Zhao et al., 2019). On the other hand, if an in-depth analysis of a SCN's robustness is necessary, then pursuing an optimization-based approach may be more appropriate. Another conclusion that we may draw from this study is that a more resilient network structure may not always require mitigation in order to cope with disruptions. In particular, the results indicate that actively adding redundancy, which is one of the primary mitigation strategies in many supply chains, will not always result in the most resilient supply chain (Observation 1).

As part of the new hybrid approach discussed above, interdependencies between the suggested resilience factors, as well as the considered resilience strategies, were separately quantified by using DEMATEL. ANP was then used to quantify the outer dependencies among different clusters of the decision network and to construct the limit super-matrix from which the global weights of all the decision network's elements were estimated. The resulting overall combination of the weights that were calculated for the competing supply chains then became the composite resilience indices (CRIs) by which the overall resilience ranking vector was determined.

While many current efforts mostly focus on suggesting mitigation strategies to cope with disruptions, our findings show that decision makers and top managers should take the whole structure into consideration when designing/redesigning their SCNs. Previous works largely focus on assessing potential vulnerabilities of the network's entities and/or the capabilities they need to manage these vulnerabilities. The present study, however, aims to quantify the resilience level of SCNs through a number of SNA-inspired factors, which can help in designing resilient SCNs.

Our findings also indicate that adding extra nodes without considering the whole network's structure and its entities' linkages may not increase the supply chain's resilience level. Moreover, we find that decision makers and managers should take a broader view of supplier selection practices since the suppliers' locations in the network play a crucial role in the whole network's resilience level. For example, a supply chain could achieve a higher composite resilience index by contracting between the parties to make more clusters in the network and thus increase the centrality of the suppliers. 


\section{Conclusions}

Today's multi-tier, complex supply chains are prone to a variety of vulnerabilities and thus require to be resilient in order to cope with potential disruptions. In this regard, designing resilient supply chains is one of the main challenges faced by decision makers. Supply networks serve as important sources of resource access, power, and trust and can also act as signaling mechanisms. These sources serve as catalysts for the development and dissemination of new ideas, applications, and supply chain practices (Basole et al., 2018).

The supply chain management literature offers many quantitative metrics that could be adapted to provide a comprehensive quantitative analysis of different supply chain structures from various perspectives. This study examines the structural complexity of SCNs from the resilience viewpoint. For this, it proposes a new hybrid MADM approach to measure and compare the resilience level of several competing SCNs using a number of quantitative factors inspired by SNA metrics. It is important to note that combinations of supply chain resilience dimensions other than those that were selected could also be considered (such as those described in Chowdhury and Quaddus (2017)), in order to show alternate aspects of supply chain resilience.

Despite its various contributions, this study has some limitations as well. The discussion focused on measuring and comparing the resilience level of several competing supply chains, but it did not fully elaborate on the network factors that actually led to better performance against disruptions. For instance, the analysis did not take into account the possible effects on network resilience of different arc lengths (i.e. transportation routes) or different lead times. Variances in lead-times at the node level, and along the arcs, or differences between various paths through a network, would also be expected to contribute to the strength of a network-level disruption. Another limitation of the study is the amount of rich and detailed data that must be provided by managers when constructing the required pairwise comparison matrices (PCMs) (Supplementary material - step 1 and step 4), in terms

of the number of pairwise comparisons that must be made. In order to tackle issues of cognitive overload, we suggest using the recently developed "Best-Worst method (BWM)", which is a comparison-based method that conducts the pairwise comparisons in a particularly 
structured way, so that not only less information (i.e. less pairwise comparisons) is required, but also the comparisons are more consistent (Rezaei, 2015).

Since designing a resilient supply chain that is also cost efficient is of particular interest for top managers, our methodology could help decision makers to choose the most resilient supply chain among several competing network structures, while taking the cost of each structure into account as well. More specifically, an interesting avenue for future research would be to formulate multi-objective mathematical models for making trade-off analyses between the well-known objective functions (i.e. the cost efficiency, the responsiveness and the resilience of the designed supply chain), while using the proposed resilience assessment method to quantify the more qualitative resilience objective. Also, simulation methods can be used to demonstrate the resilience of additional networks in some scenarios based on the proposed framework. From a practical point of view, there is also opportunity to implement the main findings of this study to reconfigure real supply chains, especially in those industrial sectors having complex multi-tier supply chains (like auto supply chains), in order to find the most resilient network structure, while still controlling the total cost.

\section{References}

Adenso-Diaz, B., Mena, C., García-Carbajal, S. and Liechty, M. (2012), "The impact of supply network characteristics on reliability", Supply Chain Management: An International Journal, Vol. 17 No. 3, pp. 263-276.

Adobor, H. (2019). Supply chain resilience: a multi-level framework. International Journal of Logistics Research and Applications, Vol. 22 No.6, pp. 533-556.

Akgul, B.K., Ozorhon, B., Dikmen, I. and Birgonul, M.T. (2017), "Social network analysis of construction companies operating in international markets: case of Turkish contractors", Journal of Civil Engineering and Management, Vol. 23 No. 3, pp. 327-337.

Bai, Y., Huang, N., Xu, K. and Zhang, X. (2017), "Resilience analytics of networks with dependency groups", 2017 2nd International Conference on System Reliability and Safety, ICSRS 2017, pp. 486-490.

Basole, R.C., Ghosh, S. and Hora, M.S. (2018), "Supply Network Structure and Firm Performance: Evidence From the Electronics Industry”, IEEE Transactions on Engineering Management, Vol. 65 No. 1, pp. 141-154.

Birkie, S.E., Trucco, P. and Fernandez Campos, P. (2017), "Effectiveness of resilience capabilities in mitigating disruptions: leveraging on supply chain structural complexity", Supply Chain Management: An International Journal, Vol. 22 No. 6, pp. 506-521.

Bondy, J.A. and Murty, U.S.R. (1976), "Graph Theory With Applications - J. Bondy, U. Murty.pdf”, Operational Research Quarterly 19701977. 
Bonyani, A., and Alimohammadlou, M. (2019). "A novel approach to solve the problems with network structure”, Operational Research. https://doi.org/10.1007/s12351-019-00486-0

Borgatti, S.P. and Li, X. (2009), "On social network analysis in a supply chain context", Journal of Supply Chain Management, Vol. 45 No. 2, pp. 5-22.

Bureau, E. (2011), "Toyota to cut India output by 70\% due to parts shortage", The Economic Times, 24 April.

Borgatti, Stephen P, and Rob Cross. 2003. "A relational view of information seeking and learning in social networks." Management science 49 (4):432-445.

Cardoso, S.R., Paula Barbosa-Póvoa, A., Relvas, S. and Novais, A.Q. (2015), "Resilience metrics in the assessment of complex supply-chains performance operating under demand uncertainty", Omega, Vol. 56, pp. 53-73.

Chakraborty, T., Chauhan, S. and Ouhimmou, M. (2019), "Mitigating supply disruption with a backup supplier under uncertain demand: competition vs. cooperation", International Journal of Production Research, pp. 1-32.

Choi, T.Y. and Hong, Y. (2002), "Unveiling the structure of supply networks: Case studies in Honda, Acura, and DaimlerChrysler", Journal of Operations Management, Vol. 20 No. 5, pp. 469-493.

Choi, T.Y. and Kim, Y. (2008), "Structural embeddedness and supplier management: A network perspective", Journal of Supply Chain Management, Vol. 44 No. 4, pp. 5-13.

Chopra, S. and Sodhi, M.S. (2004), "Managing risk to avoid: Supply-chain breakdown", MIT Sloan Management Review.

Chowdhury, M.M.H. and Quaddus, M. (2017), "Supply chain resilience: Conceptualization and scale development using dynamic capability theory", International Journal of Production Economics, available at:https://doi.org/10.1016/j.ijpe.2017.03.020.

Chowdhury, M.M.H. and Quaddus, M.A. (2015), "A multiple objective optimization based QFD approach for efficient resilient strategies to mitigate supply chain vulnerabilities: The case of garment industry of Bangladesh”, Omega, Vol. 57, pp. 5-21.

Christopher, M. and Peck, H. (2004), "Building the Resilient Supply Chain", The International Journal of Logistics Management, Vol. 15 No. 2, pp. 1-14.

Craighead, C.W., Blackhurst, J., Rungtusanatham, M.J. and Handfield, R.B. (2007), "The severity of supply chain disruptions: Design characteristics and mitigation capabilities", Decision Sciences, Vol. 38 No. 1, pp. 131-156.

Dijkstra, E.W. (1959), "A note on two problems in connexion with graphs", Numerische Mathematik, Vol. 1 No. 1, pp. 269-271.

Ellis, S.C., Henry, R.M. and Shockley, J. (2010), "Buyer perceptions of supply disruption risk: A behavioral view and empirical assessment", Journal of Operations Management, Vol. 28 No. 1, pp. 34-46.

Elluru, S., Gupta, H., Kaur, H. and Singh, S. (2019), "Proactive and reactive models for disaster resilient supply chain", Annals of Operations Research, Vol. 283 No. 1-2, pp. 199-224.

Fahimnia, B., Tang, C.S., Davarzani, H. and Sarkis, J. (2015), "Quantitative models for managing supply chain risks: A review”, European Journal of Operational Research, Vol. 247 No. 1, pp. 1-15. 
Falasca, M., Zobel, C.W. and Cook, D. (2008), "A decision support framework to assess supply chain resilience", Proceedings of the 5th International ISCRAM Conference.

Fazli, S., Kiani Mavi, R., and Vosooghidizaji, M. (2015). "Crude oil supply chain risk management with DEMATEL-ANP”, Operational Research, 15(3), 453-480.

Fiksel, J. (2003), "Designing Resilient, Sustainable Systems”, Environmental Science and Technology, Vol. 37 No. 23, pp. 5330-5339.

Freeman, L.C. (1977), “A Set of Measures of Centrality Based on Betweenness”, Sociometry, Vol. 40 No. 1, p. 35 .

Freeman, L.C., Borgatti, S.P. and White, D.R. (1991), "Centrality in valued graphs: A measure of betweenness based on network flow”, Social Networks, Vol. 13 No. 2, pp. 141-154.

Gong, J., Mitchell, J.E., Krishnamurthy, A. and Wallace, W.A. (2014), “An interdependent layered network model for a resilient supply chain”, Omega, Vol. 46, pp. 104-116.

Gulati, R., Lavie, D. and Ravi Madhavan, R. (2011), "How do networks matter? The performance effects of interorganizational networks", Research in Organizational Behavior, Vol. 31, pp. 207-224.

Hatefi, S.M. and Torabi, S.A. (2010), "A common weight MCDA - DEA approach to construct composite indicators”, Ecological Economics Journal, Vol. 70 No. 1, pp. 114-120.

Hsu, Chia-Wei, Tsai-Chi Kuo, Sheng-Hung Chen, and Allen H Hu. (2013), "Using DEMATEL to develop a carbon management model of supplier selection in green supply chain management", Journal of Cleaner Production, Vol. 56, pp.164-172.

Hosseini, S. and Barker, K. (2016), "A Bayesian network model for resilience-based supplier selection", International Journal of Production Economics, Vol. 180, pp. 68-87.

Hosseini, S., Barker, K. and Ramirez-Marquez, Jose E. (2016). "A review of definitions and measures of system resilience." Reliability Engineering \& System Safety 145:47-61.

Hosseini, S. and Ivanov, D. (2019). "A new resilience measure for supply networks with the ripple effect considerations: A Bayesian network approach", Annals of Operations Research, available at: https://doi.org/10.1007/s10479-019-03350-8.

Hosseini, S. and Ivanov, D. (2020). "Bayesian networks for supply chain risk, resilience and ripple effect analysis: A literature review", Expert systems with applications, Vol. 161, 113649.

Hosseini, S., Ivanov, D. and Blackhurst, J. (2020a). "Conceptualization and measurement of supply chain resilience in an open-system context", IEEE Transactions on Engineering Management, available at: https://doi.org/10.1109/TEM.2020.3026465.

Hosseini, S., Ivanov, D. and Dolgui, A. (2019a), "Review of quantitative methods for supply chain resilience analysis", Transportation Research Part E: Logistics and Transportation Review, Vol. 125, pp. 285-307.

Hosseini, S., Ivanov, D. and Dolgui, A. (2020b). "Ripple effect modelling of supplier disruption: integrated Markov chain and dynamic Bayesian network approach", International Journal of Production Research, Vol. 58 No. 11, 3284-3303.

Hosseini, S., Morshedlou, N., Ivanov, D., Sarder, M.D., Barker, K. and Al Khaled, A. (2019b), "Resilient supplier selection and optimal order allocation under disruption risks", International Journal of Production Economics, Vol. 213, pp. 124-137. 
Hosseini, S., and Al Khaled, A. (2019). "A hybrid ensemble and AHP approach for resilient supplier selection." Journal of Intelligent Manufacturing 30 (1):207-228.

Ivanov, D., Pavlov, A., Pavlov, D. and Sokolov, B. (2017a), "Minimization of disruption-related return flows in the supply chain", International Journal of Production Economics, Vol. 183, 503-513.

Ivanov, D., Dolgui, A., Sokolov, B. and Ivanova, M. (2017b), "Literature review on disruption recovery in the supply chain", International Journal of Production Research, Vol. 55 No. 20, pp. 61586174.

Jackson, M.O. (2008), Social and Economic Networks, Social and Economic Networks, Princeton University Press, Princeton, N.J.

Johnson, N., Elliott, D. and Drake, P. (2013), "Exploring the role of social capital in facilitating supply chain resilience", Supply Chain Management: An International Journal, Vol. 18 No. 3, pp.324336.

Kamalahmadi, M. and Parast, M.M. (2016), "A review of the literature on the principles of enterprise and supply chain resilience: Major findings and directions for future research", International Journal of Production Economics, Vol. 171, pp. 116-133.

Kao, T.W.D., Simpson, N.C., Shao, B.B.M. and Lin, W.T. (2017), "Relating supply network structure to productive efficiency: A multi-stage empirical investigation”, European Journal of Operational Research, Vol. 259 No. 2, pp. 469-485.

Khalili, S.M., Jolai, F. and Torabi, S.A. (2017), "Integrated production-distribution planning in twoechelon systems: a resilience view", International Journal of Production Research, Vol. 55 No. 4, pp. 1040-1064.

Kim, Y., Chen, Y.S. and Linderman, K. (2015), "Supply network disruption and resilience: A network structural perspective", Journal of Operations Management, Vol. 33-34, pp. 43-59.

Kim, Y., Choi, T.Y., Yan, T. and Dooley, K. (2011), "Structural investigation of supply networks: A social network analysis approach", Journal of Operations Management, Vol. 29 No. 3, pp. 194211.

Levalle, R.R. and Nof, S.Y. (2015), "A resilience by teaming framework for collaborative supply networks", Computers \& Industrial Engineering, Vol. 90, pp. 67-85.

Li, Y., Zobel, C.W., Seref, O. and Chatfield, D. (2019), "Network Characteristics and Supply Chain Resilience under Conditions of Risk Propagation," International Journal of Production Economics, available at: https://doi.org/10.1016/j.ijpe.2019.107529.

Mancheri, N.A., Sprecher, B., Deetman, S., Young, S.B., Bleischwitz, R., Dong, L., Kleijn, R. and Tukker, A. (2018), "Resilience in the tantalum supply chain", Resources, Conservation and Recycling, Vol. 129, pp. 56-69.

Mandal, S., Sarathy, R., Korasiga, V.R., Bhattacharya, S. and Dastidar, S.G. (2016), "Achieving supply chain resilience", International Journal of Disaster Resilience in the Built Environment, Vol. 7 No. 5, pp. 544-562.

Moreno, J.L. (1934), Data Semantics and Linguistic Semantics, Who Shall Survive?: A New Approach to the Problem of Human Interrelations., Nervous and Mental Disease Publishing Co, Washington, DC, US, available at: https://doi.org/10.1037/10648-000.

Namdar, J., Torabi, S Ali, Sahebjamnia, N. and Nilkanth Pradhan, N. (2020). "Business continuity-inspired resilient supply chain network design." International Journal of Production Research:1-37. 
Levalle, Rodrigo Reyes, and Shimon Y Nof. 2015. "A resilience by teaming framework for collaborative supply networks." Computers \& Industrial Engineering 90:67-85.

Opricovic, S. and Tzeng, G.H. (2003), "Defuzzification within a multicriteria decision model”, International Journal of Uncertainty, Fuzziness and Knowlege-Based Systems, Vol. 11 No. 5, pp. 635-652.

Pagano, A., Pluchinotta, I., Giordano, R. and Fratino, U. (2018), "Integrating "Hard" and "Soft" infrastructural resilience assessment for water distribution systems", Complexity, https://doi.org/10.1155/2018/3074791.

Parkhe, Arvind, Stanley Wasserman, and David A Ralston. (2006), "New frontiers in network theory development." Academy of Management Review 31 (3):560-568.

Pettit, T.J., Croxton, K.L. and Fiksel, J. (2013), "Ensuring supply chain resilience: Development and implementation of an assessment tool", Journal of Business Logistics, Vol. 34 No. 1, pp. 46-76.

Ponomarov, S.Y. and Holcomb, M.C. (2009), "Understanding the concept of supply chain resilience", The International Journal of Logistics Management, Vol. 20 No. 1, pp. 124-143.

Pournader, M., Rotaru, K., Kach, A.P. and Razavi Hajiagha, S.H. (2016), “An analytical model for system-wide and tier-specific assessment of resilience to supply chain risks", Supply Chain Management, Vol. 21 No. 5, pp. 589-609.

Rezaei, J. (2015), "Best-worst multi-criteria decision-making method”, Omega, Vol. 53, pp. 49-57.

Saaty, T.L. (2001), Decision making with dependence and feedback: The analytic network process, RWS Publications, Pittsburgh.

Sabahi, S., \& Parast, M. M. (2019). Firm innovation and supply chain resilience: a dynamic capability perspective. International Journal of Logistics Research and Applications, pp.1-16.

Sahebjamnia, N., Torabi, S.A. and Mansouri, S.A. (2015), "Integrated business continuity and disaster recovery planning: Towards organizational resilience", European Journal of Operational Research, Vol. 242 No. 1, pp. 261-273.

Scholten, K. and Schilder, S. (2015), "The role of collaboration in supply chain resilience", Supply Chain Management: An International Journal, Vol. 20 No. 4, pp. 471-484.

Scholten, K., Scott, P.S. and Fynes, B. (2014), "Mitigation processes - antecedents for building supply chain resilience", Supply Chain Management: An International Journal, Vol. 19 No. 2, pp. 211228.

Shao, B.B.M., Shi, Z. (Michael), Choi, T.Y. and Chae, S. (2018), "A data-analytics approach to identifying hidden critical suppliers in supply networks: Development of nexus supplier index", Decision Support Systems, Vol. 114, pp. 37-48.

Sheffi, Y. and Rice, J.B. (2005), "A supply chain view of the resilient enterprise”, MIT Sloan Management Review, Vol. 47 No. 1, p. 41.

Soni, U., Jain, V. and Kumar, S. (2014), "Measuring supply chain resilience using a deterministic modeling approach", Computers and Industrial Engineering, Vol. 74 No. 1, pp. 11-25.

Tang, C. and Tomlin, B. (2008), "The power of flexibility for mitigating supply chain risks", International Journal of Production Economics, Vol. 116 No. 1, pp. 12-27.

Tang, C.S. (2006), "Robust strategies for mitigating supply chain disruptions", International Journal of Logistics Research and Applications, Vol. 9 No. 1, pp. 33-45. 
Torabi, S.A., Baghersad, M. and Mansouri, S.A. (2015), "Resilient supplier selection and order allocation under operational and disruption risks", Transportation Research Part E: Logistics and Transportation Review, Vol. 79, pp. 22-48.

Tseng, Ming-Lang, Jui Hsiang Chiang, and Lawrence W Lan. (2009), "Selection of optimal supplier in supply chain management strategy with analytic network process and choquet integral." Computers \& Industrial Engineering 57 (1):330-340.

Turnquist, M. and Vugrin, E. (2013), "Design for resilience in infrastructure distribution networks", Environment Systems \& Decisions, Vol. 33 No. 1, pp. 104-120.

Tzeng, G.H. and Huang, J.J. (2011), Multiple Attribute Decision Making: Methods and Applications, CRC Press.

Urciuoli, L., Mohanty, S., Hintsa, J. and Boekesteijn, E.G. (2014), "The resilience of energy supply chains: A multiple case study approach on oil and gas supply chains to Europe", Supply Chain Management: An International Journal, Vol. 19 No. 1, pp. 46-63.

Vugrin, E.D., Warren, D.E. and Ehlen, M.A. (2011), “A resilience assessment framework for infrastructure and economic systems: Quantitative and qualitative resilience analysis of petrochemical supply chains to a hurricane", Process Safety Progress, Vol. 30 No. 3, 280-290.

Wang, A., Koc, B. and Nagi, R. (2005), "Complex assembly variant design in agile manufacturing. Part II: Assembly variant design methodology”, IIE Transactions, Vol. 37 No. 1, pp. 17-33.

Wang, X., Herty, M. and Zhao, L. (2016), "Contingent rerouting for enhancing supply chain resilience from supplier behavior perspective", International Transactions in Operational Research, Vol. 23 No. 4, pp. 775-796.

Wu, Hsin-Hung, Hsuan-Kai Chen, and Jiunn-I Shieh. (2010). "Evaluating performance criteria of employment service outreach program personnel by DEMATEL method." Expert Systems with Applications 37 (7):5219-5223.

Yang, J.L. and Tzeng, G.H. (2011), "An integrated MCDM technique combined with DEMATEL for a novel cluster-weighted with ANP method", Expert Systems with Applications, Vol. 38 No. 3, pp. $1417-1424$.

Yoon, J., Talluri, S., Yildiz, H. and Ho, W. (2018), "Models for supplier selection and risk mitigation: a holistic approach", International Journal of Production Research Vol. 56 No. 10, pp. 3636-3661.

Zavadskas, Edmundas Kazimieras, Zenonas Turskis, and Simona Kildienè. (2014), "State of art surveys of overviews on MCDM/MADM methods." Technological and economic development of economy, 20 (1):165-179.

Zhang, X., Miller-Hooks, E. and Denny, K. (2015), “Assessing the role of network topology in transportation network resilience", Journal of Transport Geography, Vol. 46, pp. 35-45.

Zhao, K., Scheibe, K., Blackhurst, J. and Kumar, A. (2019), "Supply Chain Network Robustness Against Disruptions: Topological Analysis, Measurement, and Optimization", IEEE Transactions on Engineering Management, Vol. 66 No. 1, pp. 127-139. 


\section{Supplementary material for: A multi-attribute supply chain network resilience assessment framework based on SNA-inspired indicators}

\section{The details of implementing the hybrid DEMATEL-ANP}

Step 1: Compute the average matrices. In step 1, once the inner relationships between the resilience factors as well as resilience strategies are separately measured by each member of the expert panel, the respective direct influence matrices are obtained (Table S1).

Table S1. An example of experts' responses for interrelationships among the resilience factors

\begin{tabular}{c|c|c|c|c|c|c|c|c|c|c|c|c} 
& SON & APLN & DI & OCCSN & ODCSN & PS & D & OC & PCN & OBCN & OFC & FC \\
\hline SON & 0 & 1 & 1 & 2 & 2 & 2 & 3 & 0 & 0 & 2 & 2 & 4 \\
APLN & 0 & 0 & 4 & 4 & 0 & 0 & 0 & 1 & 0 & 0 & 0 & 0 \\
DI & 0 & 4 & 0 & 4 & 0 & 0 & 0 & 1 & 0 & 0 & 0 & 0 \\
OCCSN & 0 & 3 & 3 & 0 & 0 & 0 & 2 & 1 & 0 & 3 & 0 & 1 \\
ODCSN & 0 & 2 & 2 & 2 & 0 & 0 & 4 & 3 & 2 & 4 & 3 & 1 \\
PS & 4 & 0 & 0 & 3 & 1 & 0 & 0 & 0 & 3 & 0 & 0 & 0 \\
D & 0 & 3 & 3 & 1 & 2 & 0 & 0 & 0 & 2 & 4 & 2 & 3 \\
OC & 0 & 3 & 3 & 2 & 1 & 0 & 3 & 0 & 0 & 2 & 1 & 0 \\
PCN & 0 & 0 & 0 & 0 & 3 & 0 & 3 & 0 & 0 & 1 & 3 & 1 \\
OBCN & 0 & 2 & 2 & 0 & 1 & 0 & 2 & 0 & 3 & 0 & 0 & 3 \\
OFC & 0 & 0 & 0 & 0 & 2 & 0 & 4 & 1 & 2 & 0 & 0 & 2 \\
FC & 0 & 0 & 0 & 0 & 2 & 0 & 4 & 0 & 3 & 2 & 0 & 0
\end{tabular}

Step 2: Calculate the normalized initial direct-relation matrices. (Table S2-S3).

Table S2. The normalized direct-relation matrix for the resilience factors

\begin{tabular}{c|c|c|c|c|c|c|c|c|c|c|c|c} 
& SON & APLN & DI & OCCSN & ODCSN & PS & D & OC & PCN & OBCN & OFC & FC \\
\hline SON & 0.0130 & 0.1474 & 0.1474 & 0.1640 & 0.1570 & 0.0810 & 0.2536 & 0.0426 & 0.1058 & 0.1935 & 0.1346 & 0.2436 \\
APLN & 0.0000 & 0.0753 & 0.2132 & 0.2133 & 0.0104 & 0.0000 & 0.0350 & 0.0616 & 0.0113 & 0.0398 & 0.0079 & 0.0190 \\
DI & 0.0000 & 0.2132 & 0.0753 & 0.2133 & 0.0104 & 0.0000 & 0.0350 & 0.0616 & 0.0113 & 0.0398 & 0.0079 & 0.0190 \\
OCCSN & 0.0000 & 0.2021 & 0.2021 & 0.0780 & 0.0344 & 0.0000 & 0.1359 & 0.0643 & 0.0461 & 0.1704 & 0.0231 & 0.0850 \\
ODCSN & 0.0000 & 0.2230 & 0.2230 & 0.1837 & 0.0890 & 0.0000 & 0.3038 & 0.1632 & 0.1763 & 0.2764 & 0.1827 & 0.1422 \\
PS & 0.1621 & 0.0653 & 0.0653 & 0.1688 & 0.0937 & 0.0130 & 0.0953 & 0.0253 & 0.1582 & 0.0772 & 0.0518 & 0.0676 \\
D & 0.0000 & 0.2247 & 0.2247 & 0.1327 & 0.1479 & 0.0000 & 0.1312 & 0.0462 & 0.1655 & 0.2464 & 0.1300 & 0.1935 \\
OC & 0.0000 & 0.2215 & 0.2215 & 0.1678 & 0.0797 & 0.0000 & 0.1903 & 0.0369 & 0.0529 & 0.1531 & 0.0726 & 0.0590 \\
PCN & 0.0000 & 0.0715 & 0.0715 & 0.0484 & 0.1745 & 0.0000 & 0.2185 & 0.0353 & 0.0724 & 0.1229 & 0.1685 & 0.1063 \\
OBCN & 0.0000 & 0.1475 & 0.1475 & 0.0635 & 0.0947 & 0.0000 & 0.1638 & 0.0276 & 0.1728 & 0.0713 & 0.0463 & 0.1652 \\
OFC & 0.0000 & 0.0743 & 0.0743 & 0.0503 & 0.1391 & 0.0000 & 0.2499 & 0.0669 & 0.1431 & 0.0904 & 0.0565 & 0.1387 \\
FC & 0.0000 & 0.0742 & 0.0742 & 0.0468 & 0.1393 & 0.0000 & 0.2446 & 0.0269 & 0.1831 & 0.1620 & 0.0593 & 0.0683
\end{tabular}


Table S3. The normalized direct-relation matrix for the resilience strategies

\begin{tabular}{c|c|c|c|c|c|c|c|c|c|c|c|c} 
& CRSCP & DS & SCBCMS & DP & IS & URKS & FSBMS & SRA & IPDPF & RRTPA & MTR & MMT \\
\hline \hline CRSCP & 0.333 & 0.04 & 0.374 & 0.19 & 0.475 & 0.468 & 0.116 & 0.414 & 0.027 & 0.346 & 0.005 & 0.031 \\
DS & 0.328 & 0.135 & 0.266 & 0.328 & 0.228 & 0.208 & 0.344 & 0.213 & 0.257 & 0.333 & 0.045 & 0.259 \\
SCBCMS & 0.533 & 0.09 & 0.305 & 0.333 & 0.488 & 0.512 & 0.153 & 0.455 & 0.042 & 0.381 & 0.008 & 0.047 \\
DP & 0.343 & 0.061 & 0.333 & 0.176 & 0.329 & 0.331 & 0.233 & 0.311 & 0.051 & 0.207 & 0.01 & 0.059 \\
IS & 0.499 & 0.057 & 0.422 & 0.338 & 0.373 & 0.514 & 0.19 & 0.491 & 0.043 & 0.383 & 0.009 & 0.049 \\
URKS & 0.399 & 0.037 & 0.239 & 0.146 & 0.359 & 0.244 & 0.132 & 0.338 & 0.03 & 0.187 & 0.006 & 0.034 \\
FSBMS & 0.264 & 0.251 & 0.304 & 0.371 & 0.23 & 0.208 & 0.199 & 0.216 & 0.252 & 0.364 & 0.051 & 0.292 \\
SRA & 0.514 & 0.061 & 0.375 & 0.297 & 0.505 & 0.498 & 0.221 & 0.327 & 0.049 & 0.343 & 0.01 & 0.056 \\
IPDPF & 0.258 & 0.278 & 0.164 & 0.183 & 0.157 & 0.148 & 0.318 & 0.181 & 0.104 & 0.183 & 0.05 & 0.29 \\
RRTPA & 0.31 & 0.03 & 0.305 & 0.181 & 0.342 & 0.232 & 0.084 & 0.288 & 0.02 & 0.168 & 0.004 & 0.023 \\
MTR & 0.013 & 0.023 & 0.012 & 0.024 & 0.01 & 0.009 & 0.022 & 0.01 & 0.008 & 0.012 & 0.025 & 0.142 \\
MMT & 0.098 & 0.179 & 0.092 & 0.181 & 0.08 & 0.075 & 0.173 & 0.075 & 0.061 & 0.095 & 0.189 & 0.089
\end{tabular}

Step 3. Calculate the total relation matrices

Step 4: Depict the impact-relations maps. the relationship maps between the resilience factors and the resilience strategies are separately represented by Figs. S1 and S2 while the related threshold values are set as the mean values of the entries in the respective total relation matrices multiplied by 1.5 in a consultation with the expert panel's members. Noteworthy, Figs. S1 and S2 are just used for representing the graphical relationships between the resilience factors (and the resilience strategies) while they are not used in the procedure of calculating the global weights of decision network's elements.

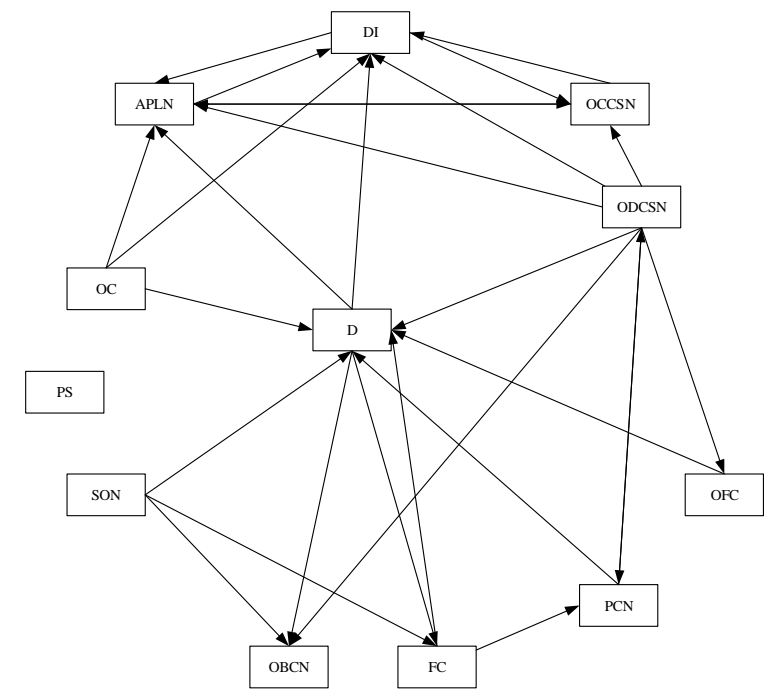

Figure S1. The relationship map between the resilience factors 


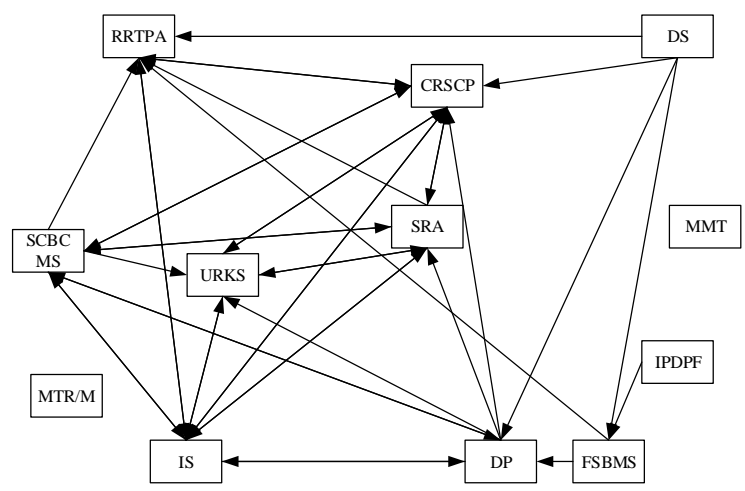

Figure S2. The relationship map between the resilience strategies

in Step 5, for obtaining the unweighted supermatrix through pairwise comparisons, the members of panel were asked to respond through a series of pairwise comparisons. The procedure is as follows:

Step 5: Form an unweighted super-matrix through the pairwise comparisons.

To calculate the resilience strategies' local weights in respect to each resilience capacity making category, the PCMs of resilience strategies in respect to resilience capacity making categories are separately constructed (Tables S4-S6) using the Likert scale of 1 to 9 representing the equal importance to the extreme importance (Saaty, 2001). It is worth noting that the geometric mean method has been used to calculate the weight vector of each PCM in our experiments.

Table S4. PCM of resilience strategies in respect to absorptive resilience capacity making category

\begin{tabular}{c|c|c|c|c|c|c|c|c|c|c|c|c} 
Absorptive & CRSCP & DS & SCBCMS & DP & IS & URKS & FSBMS & SRA & IPDPF & RRTPA & MTR & MMT \\
\hline \hline CRSCP & 1 & 1 & 1 & 5 & 3 & 1 & 1 & 1 & 3 & 5 & 3 & 5 \\
DS & 1 & 1 & 1 & 1 & 1 & 1 & 1 & 1 & 1 & 1 & 1 & 1 \\
SCBCMS & 1 & 1 & 1 & 3 & 0 & 1 & 1 & 3 & 5 & 5 & 3 & 5 \\
DP & 0.20 & 1 & 0.33 & 1 & 0 & 0.20 & 1 & 0.33 & 3 & 3 & 0.20 & 0.20 \\
IS & 0.33 & 1 & 3 & 3 & 1 & 3 & 1 & 3 & 5 & 0.20 & 0.20 & 0.20 \\
URKS & 1 & 1 & 1 & 5 & 0 & 1 & 1 & 3 & 5 & 0.33 & 3 & 1 \\
FSBMS & 1 & 1 & 1 & 1 & 1 & 1 & 1 & 1 & 1 & 1 & 1 & 1 \\
SRA & 1 & 1 & 0.33 & 3 & 0.33 & 0.33 & 1 & 1 & 0.20 & 0.33 & 0.20 & 0.20 \\
IPDPF & 0.33 & 1 & 0.20 & 0.33 & 0.20 & 0.20 & 1 & 5 & 1 & 0.33 & 5 & 1 \\
RRTPA & 0.20 & 1 & 0.20 & 0.33 & 5 & 3 & 1 & 3 & 3 & 1 & 3 & 3 \\
MTR & 0.33 & 1 & 0.33 & 5 & 5 & 0.33 & 1 & 5 & 0.20 & 0.33 & 1 & 3 \\
MMT & 0.20 & 1 & 0.20 & 5 & 5 & 1 & 1 & 5 & 1 & 0.33 & 0.33 & 1
\end{tabular}


Table S5. PCM of resilience strategies in respect to adaptive resilience capacity making category

\begin{tabular}{c|c|c|c|c|c|c|c|c|c|c|c|c} 
Adaptive & CRSCP & DS & SCBCMS & DP & IS & URKS & FSBMS & SRA & IPDPF & RRTPA & MTR & MMT \\
\hline \hline CRSCP & 1 & 1 & 0.33 & 1 & 1 & 0.33 & 0.2 & 1 & 0.33 & 5 & 1 & 1 \\
DS & 1 & 1 & 1 & 1 & 1 & 1 & 1 & 1 & 1 & 1 & 1 & 1 \\
SCBCMS & 3 & 1 & 1 & 1 & 1 & 0.2 & 0.2 & 1 & 0.2 & 3 & 1 & 1 \\
DP & 1 & 1 & 1 & 1 & 1 & 1 & 1 & 1 & 1 & 1 & 1 & 1 \\
IS & 1 & 1 & 1 & 1 & 1 & 1 & 1 & 1 & 1 & 1 & 1 & 1 \\
URKS & 3 & 1 & 5 & 1 & 1 & 1 & 0.33 & 1 & 0.2 & 7 & 1 & 1 \\
FSBMS & 5 & 1 & 5 & 1 & 1 & 3 & 1 & 1 & 1 & 5 & 1 & 1 \\
SRA & 1 & 1 & 1 & 1 & 1 & 1 & 1 & 1 & 1 & 1 & 1 & 1 \\
IPDPF & 3 & 1 & 5 & 1 & 1 & 5 & 1 & 1 & 1 & 5 & 1 & 1 \\
RRTPA & 0.2 & 1 & 0.33 & 1 & 1 & 0.14 & 0.2 & 1 & 0.2 & 1 & 1 & 1 \\
MTR & 1 & 1 & 1 & 1 & 1 & 1 & 1 & 1 & 1 & 1 & 1 & 1 \\
MMT & 1 & 1 & 1 & 1 & 1 & 1 & 1 & 1 & 1 & 1 & 1 & 1
\end{tabular}

Table S6. PCM of resilience strategies in respect to restorative resilience capacity making category

\begin{tabular}{|c|c|c|c|c|c|c|c|c|c|c|c|c|}
\hline Restorative & CRSCP & DS & SCBCMS & DP & IS & URKS & FSBMS & SRA & IPDPF & RRTPA & MTR & MMT \\
\hline CRSCP & 1 & 1 & 1 & 1 & 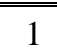 & 1 & 1 & 1 & 1 & 1 & 1 & 1 \\
\hline DS & 1 & 1 & 7 & 1 & 1 & 1 & 3 & 1 & 1 & 1 & 1 & 1 \\
\hline SCBCMS & 1 & 0.14 & 1 & 1 & 1 & 1 & 0.14 & 1 & 1 & 1 & 1 & 1 \\
\hline DP & 1 & 1 & 1 & 1 & 1 & 1 & 1 & 1 & 1 & 1 & 1 & 1 \\
\hline IS & 1 & 1 & 1 & 1 & 1 & 1 & 1 & 1 & 1 & 1 & 1 & 1 \\
\hline URKS & 1 & 1 & 1 & 1 & 1 & 1 & 1 & 1 & 1 & 1 & 1 & 1 \\
\hline FSBMS & 1 & 0.33 & 7 & 1 & 1 & 1 & 1 & 1 & 1 & 1 & 1 & 1 \\
\hline SRA & 1 & 1 & 1 & 1 & 1 & 1 & 1 & 1 & 1 & 1 & 1 & 1 \\
\hline IPDPF & 1 & 1 & 1 & 1 & 1 & 1 & 1 & 1 & 1 & 1 & 1 & 1 \\
\hline RRTPA & 1 & 1 & 1 & 1 & 1 & 1 & 1 & 1 & 1 & 1 & 1 & 1 \\
\hline MTR & 1 & 1 & 1 & 1 & 1 & 1 & 1 & 1 & 1 & 1 & 1 & 1 \\
\hline MMT & 1 & 1 & 1 & 1 & 1 & 1 & 1 & 1 & 1 & 1 & 1 & 1 \\
\hline
\end{tabular}

Step 6: Obtain the weighted super-matrix by forming the cluster matrix V. (Table S7).

Step 7: Calculate the global priorities using the limit super-matrix. 


\begin{tabular}{|c|c|c|c|c|c|c|c|c|c|c|c|c|c|c|c|c|c|c|c|c|c|c|c|c|c|c|c|c|c|c|c|c|}
\hline & & \multicolumn{3}{|c|}{ Cluserer 2} & \multicolumn{12}{|c|}{ Cusser 3} & \multicolumn{12}{|c|}{ Cusser 4} & \multicolumn{3}{|c|}{ Custer 5} \\
\hline & & CRI & & dapp & & | URKS & 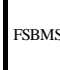 & DS & RR & SRA & |CRSCP & Is & ESCCT & MR & DP & IPDPF & MMT & Son & APLN & DI & occ & ODCSN & PS & D & $\mathrm{oc}$ & PCN & овсл & ofC & FC & $\mathrm{Accc}$ & $\begin{array}{l}\text { Acura } \\
\text { CT/TL }\end{array}$ & $\begin{array}{c}\text { DCX } \\
\text { Grand } \\
\text { Cherotee }\end{array}$ \\
\hline & CRI & \begin{tabular}{|l}
0.125 \\
\end{tabular} & 0.000 & 0.000 & 0.000 & \begin{tabular}{|l}
0.000 \\
\end{tabular} & 0.000 & 0.000 & \begin{tabular}{|l|l|} 
\\
\end{tabular} & \begin{tabular}{|l|l|} 
\\
\end{tabular} & \begin{tabular}{|l}
0.000 \\
\end{tabular} & 0.000 & 0.000 & 0.000 & \begin{tabular}{|l}
0.000 \\
\end{tabular} & \begin{tabular}{|l}
0.000 \\
\end{tabular} & \begin{tabular}{|l}
0.000 \\
\end{tabular} & \begin{tabular}{|l|l}
0.000 \\
\end{tabular} & $\begin{array}{l}0.000 \\
\end{array}$ & \begin{tabular}{|l}
0.000 \\
\end{tabular} & \begin{tabular}{|l}
0.000 \\
\end{tabular} & 0.000 & 0.000 & \begin{tabular}{|l|l} 
\\
\end{tabular} & 0.000 & 0.000 & 0.000 & \begin{tabular}{|l}
0.000 \\
\end{tabular} & \begin{tabular}{|l}
0.000 \\
\end{tabular} & \begin{tabular}{|l} 
\\
\end{tabular} & .000 & 0.000 \\
\hline & sorpt & 0.214 & 0.034 & 0.000 & 0.000 & 0.000 & 100 & 0.000 & 0.000 & 0.000 & 000 & 0.000 & .000 & 0.000 & .000 & .000 & 0.000 & 0.000 & 0.000 & 0.000 & 0.000 & 0.000 & 0.000 & 0.000 & 0.000 & 0.000 & 0.000 & 0.000 & 0.000 & 0000 & 0.000 & 0.000 \\
\hline & Adapive & 0.152 & 0.000 & .053 & 0.000 & 0.000 & 0.000 & .000 & 0.000 & 0.000 & so & . 000 & 0.000 & 0.000 & .000 & .000 & .000 & 0.000 & 0.000 & .000 & .000 & 0.000 & 0.000 & 0.000 & 0.000 & 0.000 & 0.000 & 0.000 & 0.000 & 0.000 & $0.00 \mathrm{c}$ & 0.000 \\
\hline & orat & 0.134 & 0.000 & 0.000 & 0.100 & 0.000 & 000 & 0.000 & .000 & 0.000 & 0.000 & . 000 & .000 & 0.000 & 0.000 & 0.000 & 0.000 & 0.000 & 0.000 & 0.000 & .000 & 0.000 & 0.000 & 0.000 & 0.000 & 0.000 & 0.000 & 0.000 & 0.000 & 0.000 & 0.000 & 0.000 \\
\hline & URRS & 0.036 & 0.061 & & 0.000 & 0.113 & go & 0.000 & 0.021 & 0.069 & 663 & 0 & 0.031 & .000 & .008 & 000 & 0.000 & .000 & 0.003 & 103 & .003 & 0.000 & 0.000 & 0.005 & .005 & 0.008 & 0.004 & 0.004 & 0.006 & 0.000 & 0.000 & 0.000 \\
\hline & FBBM & .079 & .017 & . & 0.130 & 0.001 & 142 & 221 & 0.078 & 0.004 & 014 & .013 & 0.002 & 0.000 & 0.048 & 0.036 & 0.011 & 0.062 & 0.000 & 0.000 & 0.000 & 0.000 & 0.088 & 0.005 & 0.000 & 0.001 & 0.005 & 0.000 & 0.006 & 0.000 & .000 & .0oc \\
\hline & DS & 0.079 & 0.020 & 0.04 & 0.176 & 0.017 & 0.083 & 3.390 & 0.075 & 0.024 & 0.052 & 4 & 0.013 & 0.000 & 0.087 & 20 & 0.046 & 0.048 & 0.017 & 0.077 & 0.019 & 0.002 & 0.062 & 0.014 & 0.001 & 0.043 & 028 & 0.000 & 0.042 & 0.000 & 0.000 & 0.000 \\
\hline & RRTPA & 0.019 & 0.040 & 0.05 & 0.000 & 0.002 & 000 & .000 & 0.094 & .002 & 25 & 029 & .002 & 0.000 & 0.001 & 0.000 & 0.000 & 0.000 & 0.000 & \begin{tabular}{|l|l} 
\\
\end{tabular} & 0.000 & 0.000 & 0.000 & 0.0000 & 0.000 & 0.001 & 0.0000 & 0.0000 & | 0.000 & 0.000 & 0.000 & 0.000 \\
\hline & SRA & \begin{tabular}{|l}
0.005 \\
\end{tabular} & 0.047 & 0.012 & 0.004 & 058 & 000 & 000 & 0.043 & \begin{tabular}{|l|l|} 
\\
\end{tabular} & 51 & $|0.053|$ & $\mid 0.059$ & 0.0000 & \begin{tabular}{|l|l|l|} 
\\
0.05
\end{tabular} & | 0.000 & 0.000 & 0.000 & 0.001 & \begin{tabular}{|l|l|l|} 
\\
0.1
\end{tabular} & \begin{tabular}{|l|l|} 
\\
\end{tabular} .01 & 0.0000 & 0.000 & $|0.001|$ & \begin{tabular}{|l|l|} 
\\
\end{tabular} .01 & 0.003 & 0.001 & \begin{tabular}{|l|l|} 
\\
0.01
\end{tabular} & \begin{tabular}{|l|l|} 
\\
\end{tabular} .01 & 0.000 & 0.000 & 0.000 \\
\hline & CRSCP & \begin{tabular}{|l}
0.033 \\
\end{tabular} & 0.098 & 0.117 & 0.063 & 153 & 0.062 & 0.002 & \begin{tabular}{|l|l} 
\\
\end{tabular} & \begin{tabular}{|l|l} 
\\
\end{tabular} & 0.154 & \begin{tabular}{|l|l} 
\\
\end{tabular} & 0.149 & 0.012 & \begin{tabular}{|l}
0.071 \\
\end{tabular} & \begin{tabular}{|l}
0.024 \\
\end{tabular} & \begin{tabular}{|l|l|} 
\\
\end{tabular} & \begin{tabular}{|l|l|} 
\\
\end{tabular} & \begin{tabular}{|l} 
\\
\end{tabular} & 0.080 & \begin{tabular}{|l}
0.158 \\
\end{tabular} & 0.140 & 0.006 & $|0.080|$ & 0.040 & 0.087 & 0.052 & \begin{tabular}{|l} 
\\
\end{tabular} & 0.081 & 0.000 & 0.000 & 0.000 \\
\hline & is & \begin{tabular}{|l}
0.011 \\
\end{tabular} & 0.088 & 035 & 0.021 & \begin{tabular}{|l}
0.111 \\
\end{tabular} & 012 & 0.000 & 0.065 & \begin{tabular}{|l}
0.119 \\
\end{tabular} & 0.092 & 0.125 & 0.120 & 0.000 & 0.088 & \begin{tabular}{|l}
0.000 \\
\end{tabular} & 0.000 & \begin{tabular}{|l|l|}
0.000 \\
\end{tabular} & 0.001 & \begin{tabular}{|l}
0.001 \\
\end{tabular} & \begin{tabular}{|l}
0.002 \\
\end{tabular} & 0.007 & 0.000 & | 0.008 & 0.003 & 0.062 & 0.072 & \begin{tabular}{|l}
0.002 \\
\end{tabular} & \begin{tabular}{|l}
0.003 \\
\end{tabular} & 0.0000 & \begin{tabular}{|l|}
0.000 \\
\end{tabular} & 0.000 \\
\hline & ESCCT & 0.040 & 0.089 & 0.090 & 0.106 & 04 & 100 & 000 & 70 & \begin{tabular}{|l|l} 
\\
\end{tabular} & 101 & .098 & 0.179 & 0.000 & 0.085 & 0.000 & 0.000 & 0.000 & \begin{tabular}{|l|l} 
\\
\end{tabular} & 0.004 & 0.005 & 0.000 & 0.000 & $\mid 0.008$ & 0.008 & 0.019 & 0.006 & \begin{tabular}{|l|l} 
\\
\end{tabular} & 0.009 & 0.000 & 0.000 & 0.000 \\
\hline & MR & 0.011 & 0.037 & 0.000 & 0.000 & 00 & po & 0.000 & 00 & 000 & so & 00 & 0.017 & 0.440 & 100 & 000 & 0.020 & 0.000 & $\begin{array}{l}0.036 \\
\end{array}$ & 36 & 0.000 & 0.000 & 0.000 & 0.101 & $0.1 \mathrm{~s}$ & 0.000 & 0.022 & 0.000 & 0.019 & 0.000 & 0.00 & 0.000 \\
\hline & DP & 0.005 & 0.050 & 0.016 & 0.012 & 18 & 0.000 & 0.000 & 1 & 46 & 0.046 & 42 & 67 & 00 & 20 & po & 0.000 & 00 & 001 & 01 & 0.002 & 0.003 & 0.000 & 0.005 & 3 & 0.034 & .001 & 0.002 & 0.003 & 0.000 & 0.000 & .000 \\
\hline & IPDPF & 0.047 & 0.036 & 0.116 & 0.088 & 0.000 & 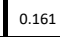 & 0.047 & 0.031 & 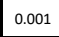 & 0.001 & 5 & 0.000 & 0 & 16 & 0.347 & 0.013 & 36 & po & 00 & \begin{tabular}{|l|l} 
\\
\end{tabular} & 0.000 & 94 & 0.016 & \begin{tabular}{|l}
0.000 \\
\end{tabular} & 0.005 & 034 & 0.000 & 0.065 & 0.000 & 0.000 & 0.000 \\
\hline & MM & 0.010 & 0.037 & & 0.000 & 0.000 & 0.000 & 0.000 & 000 & \begin{tabular}{|l|l|} 
\\
\end{tabular} & 0.000 & 00 & 100 & 00 & 00 & po & 0.142 & 000 & 00 & 000 & 000 & 0.000 & 0.000 & 0.000 & 100 & .000 & .000 & 000 & .000 & .000 & 0.000 & .000 \\
\hline & SON & 0.000 & 0.027 & & 0.100 & 000 & 0.073 & .4661 & 31 & 0.000 & 0.024 & 02 & 0.002 & 0 & 11 & 11 & 0.029 & 88 & 22 & 02 & 0.000 & 000 & 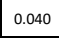 & 0.035 & 0.000 & .030 & 059 & 0.000 & 0.080 & 0.000 & 0.000 & .000 \\
\hline & APLN & 0.000 & 0.09 & & 0.012 & 0.131 & 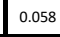 & 0.000 & 0.117 & 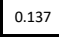 & 0.124 & 0.105 & 072 & 0 & 39 & 38 & It & 05 & 14 & 54 & 0.056 & 0.097 & 06 & 28 & 2 & .026 & 0.024 & 0.025 & 0.014 & 0.000 & 0.000 & .000 \\
\hline & DI & 0.000 & 0.0 & 0.062 & 0.012 & 0.073 & 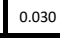 & 0.000 & 91 & 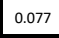 & 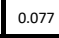 & \begin{tabular}{|l}
0.068 \\
\end{tabular} & \begin{tabular}{|l}
0.039 \\
\end{tabular} & 0 & 30 & 05 & I & 03 & 47 & 98 & \begin{tabular}{|l}
0.048 \\
\end{tabular} & 0.000 & 0.004 & 0.007 & 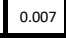 & .008 & 0.003 & 0.005 & 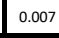 & 0.000 & 0.000 & .000 \\
\hline & occsN & 0.000 & 0.008 & 0.007 & 0.000 & 0.028 & 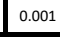 & 0.000 & 04 & . & 1 & 27 & \begin{tabular}{|l}
0.004 \\
\end{tabular} & 0 & 34 & 01 & 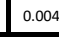 & oo & 22 & 22 & \begin{tabular}{|l}
0.104 \\
\end{tabular} & 0.000 & 0 & 0 & 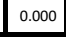 & \begin{tabular}{|l}
0.002 \\
\end{tabular} & 01 & 0.000 & \begin{tabular}{|l|l} 
& 0.00 \\
\end{tabular} & \begin{tabular}{|l|l|} 
\\
\end{tabular} & 0.000 & .000 \\
\hline & ODCSN & 0.000 & 0.010 & 0.007 & 0.013 & 0.008 & 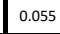 & 0.000 & 0.011 & 0 & 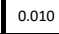 & 008 & 0.008 & 0.000 & 10 & 04 & i & 3 & 54 & 50 & \begin{tabular}{|l} 
\\
\end{tabular} & 0.150 & 04 & 73 & 0 & \begin{tabular}{|l}
0.098 \\
\end{tabular} & 0.058 & 0.038 & 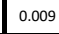 & 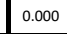 & 0.000 & 0.000 \\
\hline & PS & $\begin{array}{l}0.000 \\
\end{array}$ & 0.019 & 0.042 & 0.043 & 06 & 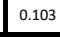 & 00 & 32 & \begin{tabular}{|l}
0.013 \\
\end{tabular} & 12 & \begin{tabular}{|l}
0.009 \\
\end{tabular} & 0.005 & 00 & 18 & 17 & 0.036 & 19 & 03 & 03 & \begin{tabular}{|l} 
\\
\end{tabular} & 0.000 & 55 & 001 & 0.001 & 0.000 & 004 & 01 & 06 & \begin{tabular}{|l} 
\\
\end{tabular} & 0.000 & .000 \\
\hline & D & 0.000 & 0.043 & 0.053 & 0.100 & 55 & \begin{tabular}{|l}
0.025 \\
\end{tabular} & 00 & 51 & 0.058 & 53 & \begin{tabular}{|l}
0.059 \\
\end{tabular} & 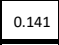 & 00 & 74 & 009 & \begin{tabular}{|l}
0.097 \\
\end{tabular} & .000 & 066 & 669 & \begin{tabular}{|l}
0.020 \\
\end{tabular} & 0.000 & 100 & 087 & 0.000 & 0.015 & 883 & 00 & 54 & 0.000 & 0.000 & 0.000 \\
\hline & OC & 0.000 & 0.034 & 0.000 & 0.000 & 05 & \begin{tabular}{|l}
0.002 \\
\end{tabular} & + & 02 & \begin{tabular}{|l}
0.002 \\
\end{tabular} & 002 & 0.006 & \begin{tabular}{|l}
0.002 \\
\end{tabular} & 52 & 01 & 801 & \begin{tabular}{|l}
0.009 \\
\end{tabular} & no & 34 & 35 & 0.034 & 0.000 & 0 & 42 & \begin{tabular}{|l}
0.169 \\
\end{tabular} & 0.000 & 03 & \begin{tabular}{|l|l} 
\\
\end{tabular} & \begin{tabular}{|l} 
\\
\end{tabular} & \begin{tabular}{|l|l} 
\\
\end{tabular} & 0.000 & 0.000 \\
\hline & PCN & 0.000 & 0.003 & 0.005 & 0.000 & 04 & 16 & 00 & 03 & \begin{tabular}{|l}
0.004 \\
\end{tabular} & 12 & 04 & 0.006 & 0 & 96 & Do & 1 & 0.000 & 88 & \begin{tabular}{|l}
0.008 \\
\end{tabular} & 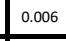 & 0.055 & 0 & 0.045 & 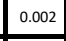 & 998 & 0.008 & 0.115 & 0.004 & 0.000 & 0.000 & 0.000 \\
\hline & $\mathrm{OBC}$ & 0.000 & 0.000 & 0.004 & 0.007 & 0.000 & 0.028 & 0.000 & 0.003 & 0.000 & 0.000 & 0.000 & \begin{tabular}{|l|l}
0.000 \\
\end{tabular} & 0.000 & 0.003 & 0.000 & 0.000 & 0.002 & 0.000 & 0.000 & 0.000 & 0.000 & 0.003 & 0.000 & 0.000 & 0.000 & 0.091 & 0.000 & 0.000 & 0.000 & 0.000 & 0.000 \\
\hline & $\mathrm{OFC}$ & 0.000 & 0.010 & 0.007 & 0.013 & 77 & 27 & 0.000 & 0.004 & 007 & 06 & 106 & 0.012 & 0 & 38 & 000 & 0.044 & 3 & 003 & 03 & 0.000 & 000 & 4 & 3 & 0 & 0.004 & .003 & 0.123 & 0.003 & \begin{tabular}{|l}
0.000 \\
\end{tabular} & 0.000 & .000 \\
\hline & $\mathrm{FG}$ & 0.000 & 0.040 & 0.000 & 0.000 & 0.041 & 000 & 0.000 & \begin{tabular}{|l|l|l|} 
\\
0.19
\end{tabular} & \begin{tabular}{|l}
0.042 \\
\end{tabular} & 36 & 73 & 0.054 & 000 & 121 & .000 & \begin{tabular}{|l}
0.001 \\
\end{tabular} & 5.000 & 0.001 & 0.001 & 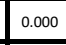 & 0.003 & 0.000 & .022 & \begin{tabular}{|l}
0.000 \\
\end{tabular} & 0.054 & .010 & \begin{tabular}{|l}
0.000 \\
\end{tabular} & \begin{tabular}{|l}
0.098 \\
\end{tabular} & 0.000 & 000 & .000 \\
\hline & Accor & 0.000 & 0.000 & 0.000 & 0.00 & \begin{tabular}{|l}
0.009 \\
\end{tabular} & 0.037 & \begin{tabular}{|l} 
\\
\end{tabular} & 0.011 & \begin{tabular}{|l}
0.011 \\
\end{tabular} & 0.011 & \begin{tabular}{|l}
0.014 \\
\end{tabular} & 0.006 & 0.032 & \begin{tabular}{|l}
0.018 \\
\end{tabular} & .038 & 0.055 & 3 & 42 & 37 & \begin{tabular}{|l|l|}
0.144 \\
\end{tabular} & 0.192 & 68 & 35 & \begin{tabular}{|l|l}
0.200 \\
\end{tabular} & 0.145 & 0.138 & 173 & 147 & 1.000 & 0.000 & .000 \\
\hline & CIT/L & 0.0 & 0.000 & 0.000 & 0.000 & \begin{tabular}{|l|l|l|}
0.013 \\
\end{tabular} & \begin{tabular}{|l|l|l|l} 
\\
\end{tabular} & & 0.015 & \begin{tabular}{|l}
0.015 \\
\end{tabular} & 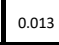 & 16 & L & 54 & 18 & 46 & 0.064 & 2 & 55 & 58 & \begin{tabular}{|l}
0.158 \\
\end{tabular} & 0.171 & 8 & 29 & \begin{tabular}{|l}
0.250 \\
\end{tabular} & 0.116 & 0.145 & \begin{tabular}{|l}
0.167 \\
\end{tabular} & 141 & 0.000 & 000 & .000 \\
\hline & & 0. & 0.000 & 0.000 & & & & & $\mid 0.015$ & 0.010 & 1 & 0.019 & & 0.000 & |.0021 & | & & $0.1 / 2$ & 0.145 & |. 0.47 & | 0.167 & 0.179 & 0.185 & $\mid 0.126$ & 150 & 42 & 0.144 & 1.176 & 46 & \begin{tabular}{|l}
$\mid 0.000$ \\
\end{tabular} & 0.000 & 1.000 \\
\hline
\end{tabular}

